\title{
1 The Nile perch invasion in Lake Victoria: cause or consequence of
}

2 the haplochromine decline?

3 Paul A.M. van Zwieten ${ }^{1 *}$, Jeppe Kolding ${ }^{2}$, Michael Plank ${ }^{3}$, Robert E. Hecky ${ }^{4}$, Thomas B. Bridgeman ${ }^{5}$,

$4 \quad$ Sally MacIntyre ${ }^{6}$, Ole Seehausen ${ }^{7,8}$, Greg M. Silsbe $^{9}$

$5{ }^{1}$ Aquaculture and Fisheries Group, Wageningen University, PO Box 338, 6700 Wageningen, The

$6 \quad$ Netherlands. E-mail: paul.vanzwieten@wur.nl

$7{ }^{2}$ Department of Biology, University of Bergen, High Technology Center, PO Box 7800, N-5020 Bergen,

$8 \quad$ Norway. E-mail: jeppe.kolding@bio.uib.no

$9{ }^{3}$ School of Mathematics and Statistics, University of Canterbury, Christchurch, New Zealand and Te 10 Pūnaha Matatini Centre of Research Excellence, New Zealand. E-mail: 11 michael.plank@canterbury.ac.nz

$12{ }^{4}$ Large Lakes Observatory and Department of Biology, University of Minnesota, Duluth, Minnesota 13 MN 55812, USA. E-mail: rehecky@gmail.com

$14{ }^{5}$ Department of Environmental Sciences, University of Toledo, Toledo, Ohio, USA. E-mail: 15 thomas.bridgeman@utoledo.edu

$16{ }^{6}$ Earth Research Institute and Department of Ecology, Evolution and Marine Biology, University of 17 California, Santa Barbara, California 93106, USA. E-mail: sally.macintyre@ucsb.edu

$18{ }^{7}$ Aquatic Ecology and Evolution, Institute of Ecology and Evolution, University of Bern, 3012 Bern, 19 Switzerland

$20{ }^{8}$ Department of Fish Ecology and Evolution, Centre of Ecology, Evolution \& Biogeochemistry, Eawag: 21 Swiss Federal Institute of Aquatic Science and Technology, 6047 Kastanienbaum, Switzerland: E-mail: 22 Ole.Seehausen@eawag.ch 
${ }^{9}$ Department of Botany and Plant Pathology, Oregon State University, Corvallis, OR 97331, USA. Email:gsilsbe@gmail.com

*Corresponding author E-mail: paul.vanzwieten@wur.nl

\begin{abstract}
We review alternative hypotheses and associated mechanisms to explain Lake Victoria's Nile perch takeover and concurrent reduction in haplochromines through a (re)analysis of long term climate, limnological and stock observations in comparison with size-spectrum model predictions of co-existence, extinction and demographic change. The empirical observations are in agreement with the outcomes of the model containing two interacting species with life-histories matching Nile perch and a generalized haplochromine. The dynamic interactions may have depended on size related differences in early juvenile mortality: mouth-brooding haplochromines escape predation mortality in early life stages, unlike Nile perch that have miniscule planktonic eggs and larvae. In our model predation on the latter by planktivorous haplochromine fry act as a stabilizing factor for co-existence, but external mortality on the haplochromines would disrupt this balance in favor of Nile perch. To explain the observed switch, mortality on haplochromines would need to be much higher than the fishing mortality that can be realistically re-constructed from observations. Abrupt concomitant changes in algal and zooplankton composition, decreased water column transparency, and widespread hypoxia from increased eutrophication most likely caused haplochromine biomass decline. We hypothesize that the shift to Nile perch was a consequence of an externally caused, climate triggered, decrease in haplochromine biomass and associated recruitment failure rather than a direct cause of the introduction.
\end{abstract}

\title{
Keywords
}

Lakes, Eutrophication, Predator-prey interaction, Invasive species, Climate change 
Invasions of non-native species into ecosystems become increasingly common through anthropogenic activities, facilitated by climate change (Cheung et al. 2009). For most invasions little

is known about interactions with the resident community until the invader is well established (García-Berthou 2007). One of the best known cases, the Nile perch (Lates niloticus) introduction and

subsequent profound community changes in Lake Victoria (Barel et al. 1985; Goudswaard et al. 2008; Witte et al. 1992) (Figure 1), has been studied since 1969 together with the resident assemblage of haplochromine cichlids. It thus provides a unique possibility to test hypotheses on the nature of the interactions between the invader, resident communities and system drivers of community change. We review some of these hypotheses and mechanisms through a (re)analysis of existing long term observations on limnological changes and stock developments before, during and after the switch from a cichlid dominated to a perch dominated assemblage and we compare these observations with dynamic size-based model predictions of co-existence, extinction and demographic change in Nile perch and haplochromine populations.

Between 1954 and the early 1960s small numbers of Nile perch, a large piscivorous predator, were introduced on several occasions in the Ugandan and Kenyan parts of the lake with the aims of creating a recreational fishery and to convert the large biomass of the indigenous small bony haplochromine cichlids into a less productive but more valuable commodity (Anderson 1961; Fryer 1960; Pringle 2005; Welcomme 1988). Nile perch spread rapidly across the Lake and by October 1961 was reported in Mwanza, Tanzania, over $300 \mathrm{~km}$ from the sites of introduction. However, it remained scarce for the next 20 years. By 1972-1975 it was caught all over the lake as large adults (Kudhongania and Cordone 1974b; Pringle 2005), in coarse-meshed, 5-7 inch gillnets (Scully 1976a, b) but in negligible quantities (Marten 1979). During this period, haplochromines dominated in terms of fisheries and biomass, which increased and then decreased well before a sudden switch to Nile perch dominance in the early 1980s and concomitant disappearance of several hundred species of 
haplochromines (Kolding et al. 2008). Top down (fishing) and bottom up (eutrophication) mechanisms have been proposed as switch-inducing catalyzers (Goudswaard et al. 2008; Hecky 1993; Kolding et al. 2008; Seehausen et al. 2003). Importantly, it was only after the Nile perch upsurge that large numbers of recruits $<15 \mathrm{~cm}$ appeared in the lake (Goudswaard et al. 2008), leading to a major change in the size-structure of the Nile perch population. Since then a large and economically important Nile perch fishery developed with landings fluctuating around a long term annual average of 240,000 ton (Kolding et al. 2013). Later, from the late 1990s, a reappearance of a small number of haplochromine species (Balirwa et al. 2003; Downing et al. 2014; Seehausen et al. 1997b) has resulted in a renewed fishery with reported catches of around 100,000 ton, two to five times larger than before the collapse (Kolding et al. 2013).

A long time lag from introduction to dominance by an invader is a common feature of invasions (Boggs et al. 2006; Sakai et al. 2001). For Lake Victoria two general hypotheses have been proposed to explain this time lag: (1) a trophic cascade resulting from top down control of haplochromines through Nile perch predation and (2) recruitment depensation. Downing et al. (2013) showed that simple logistic population growth would be sufficient to explain the timing and speed of the Nile perch invasion as a trophic cascade. A further refinement of this hypothesis is the particular observed spatial sequence of the haplochromine collapse starting from the north by a wave of migrating Nile perch dispersing over the Lake (Goudswaard et al. 2008). Downing et al. (2013) argue that, although depensatory mechanisms could play a role locally, on a whole-lake scale no depensation would be needed to explain the initial slow expansion of Nile perch. On the other hand, using a consumer-resource model, van de Wolfshaar et al. (2014) found that co-existence of Nile perch with a generalized haplochromine was possible. In fact in other African lakes haplochromine communities do co-exist with large Lates species including Nile perch.

The depensatory hypotheses focus on the community size structure where Nile perch recruitment is limited through predation and/or competition between juvenile Nile perch and 
haplochromines. Under these hypotheses, external factors are needed to break an initial coexistence. A range of contending explanatory hypotheses focusses on the nature of the depensatory restriction on Nile perch recruitment (hereinafter referred to as the haplochromine filter) through competition or predation and the associated disturbance required to release it (Goudswaard et al. 2008; Kolding et al. 2008; van de Wolfshaar et al. 2014; Walters and Kitchell 2001). The haplochromine filter breaks if there is a recruitment failure or a decreased biomass of adult piscivorous haplochromine predating on early life stages of Nile perch (Witte et al. 2007) a mechanism also proposed for other aquatic systems (Persson et al. 2007).

Mechanisms suggested for catalysing the switch through eternal mortalities on all or piscivorous haplochromines include top-down stress from fishing on haplochromines (Goudswaard et al. 2008), and/or bottom-up stress caused by eutrophication leading to structural trophic and biophysical changes in the lake (Hecky 1993; Kolding et al. 2008; Seehausen et al. 1997a). These include changes in phytoplankton and zooplankton communities changing food availability and quality at the base of the haplochromine food web (Hecky et al. 2010; Kling et al. 2001), changes in light attenuation affecting visibility and feeding efficiency of haplochromines (Seehausen et al. 1997a) and changes in extent and duration of hypoxia and anoxia during stratification (Verschuren et al. 2002).

Here we will review these hypotheses and present a refinement of the mechanism for recruitment depensation, where the switch from haplochromines to Nile perch depends on sizerelated differences in early juvenile predation mortality. Haplochromines, being maternal mouth brooders, protect their offspring from predation mortality in their early life stages whereas Nile perch with miniscule planktonic eggs and larvae (Hopson 1969) do not (Figure 2). The comparatively large haplochromine fry are nearly all initially planktivores, irrespective of the highly diverse adult feeding specializations. Thus, a decline in overall haplochromine biomass would release Nile perch from early high mortality on the planktonic egg and larval stage. This would induce a subsequent 
switch, but the cause would be an externally driven decrease in haplochromines, and not a trophic cascade induced by Nile perch predation. We test the likelihood of this hypothesis using a dynamic size-spectrum model of two interacting species, comprising a resident species with a haplochrominelike life history and an introduced species with a Nile-perch-like life history. We will examine the different alternative suggestions for the catalyzing decrease in haplochromine biomass that occurred prior to the switch. Lastly we will discuss the consequences of the proposed mechanisms in the light of the observed renewal of the haplochromine biomass and the eutrophication status of the Lake.

\section{Methods}

Critical in distinguishing between various hypotheses is the observed temporal sequence of changes in the fish community as well as the variables that potentially affect these changes through (1) eutrophication-related processes using time series of climate, water chemistry and primary and secondary production; and (2) fishing, through quantitative changes in abundance, biomass and size structure of haplochromines and Nile perch.

\section{Climate and limnology}

A set of indicators describing developments in eutrophication in relation to climate and changes in lower trophic levels as potential drivers of haplochromine collapse is given in Table 1. Methods of reconstruction of climate time series and limnological variables are described in Appendix A. All indicators are presented as standardised anomalies through (value - mean)/(standard deviation).

\section{Fisheries and fish data}

All observations on Nile perch size and abundances as well as haplochromine abundances are obtained from experimental trawl surveys which began on the lake in 1969 (Kudhongania and Cordone 1974b) and have since been conducted on a fairly frequent basis. The reconstruction and consolidation of these data sets is described in Kolding et al. $(2005,2008)$ and extended with experimental surveys conducted up till 2011. A short summary is given in Appendix B. Experimental 
catch data for the Kenyan part of the lake, including the Winam Gulf (aka Kavirondo or Nyanza Gulf) exist, but only published aggregates of Nile perch and haplochromine biomass estimates were available to us (Goudswaard et al. 2008; Muller and Benda 1981). Acoustic survey estimates of Nile perch biomass, used for validation of trawl surveys, were taken from Everson et al. (2013) and EAF/LVFO (2013). Catch estimates by species category from the three countries were compiled by the LVFO (Kolding et al. 2005) and an updated time series of annual catches was published in Kolding et al. (2013). Data on sizes of haplochromine fry were collected in the laboratory of the Swiss Federal Institute for Aquatic Science and Technology (Eawag) (Appendix C) and were used to parameterise the model.

Length L of Nile perch was converted to weight W by the Beyer (1987) algorithm with $\mathrm{a}=0.011 \mathrm{~g} / \mathrm{cm}^{\mathrm{b}}$ and $\mathrm{b}=3.044$. Here we define mature adults $\mathrm{as} \geq 70 \mathrm{~cm}$ (Mkumbo and Marshall 2014; Witte and Winter 1995), sub-adults as $<70 \mathrm{~cm}$ and $\geq 15 \mathrm{~cm}$, and recruits as $<15 \mathrm{~cm}$ standard length. Juvenile (immature) Nile perch are defined as $<70 \mathrm{~cm}$ standard length.

Spatially defined catch rates from the experimental fishery were corrected for trawl duration to a standard haul of 60 minutes using total biomass $(\mathrm{kg})$ of all species (see Appendix $\mathrm{E}$ for details). Weights are continuous and log-normally distributed. We used a hurdle model to make use of the information contained in zero catches and thus obtain three time series of indicators related to changes in Nile perch population: the catch probability, or encounter rate $\left(P_{c}\right)$; the catch rate of positive catches or patch density $\left(\mathrm{CPUE}_{\mathrm{po}}\right)$; and the relative biomass or catch rate adjusted for the encounter rate $\left(C P U E_{a d}=P_{c} \times C P U E_{p o}\right)$. The encounter rate can be interpreted in terms of dispersion and establishment of the species over the lake. The positive catch rates ( $\mathrm{CPUE}_{\mathrm{po}}, \mathrm{kg} / \mathrm{hr}$ ) are an estimate of the density in a swept area of a 60 minute haul, thus representing the patch density, which is the average density of Nile perch when encountered in a standardized trawl swept area of 6.8 ha. The catch rates adjusted by the probability of catch $\mathrm{CPUE}_{\mathrm{ad}}(\mathrm{kg} / \mathrm{hr})$ represent the overall average relative density (see Appendix D for details). To confront the empirical results with the size- 
based model results two relative density ratios were examined: the juvenile Nile perch: adult Nile perch $(\mathrm{J} / \mathrm{A})$ and the haplochromine: Nile perch $(\mathrm{H} / \mathrm{N})$ biomass ratio (See Appendix D for details).

To test the hypothesis that the external haplochromine mortality prior to the switch was caused by fishing alone, we estimated the biomass decline and the decline in haplochromine productive capacity of the Tanzanian part of the lake between 1969 and 1982 . We assume that fishing was confined to $<30 \mathrm{~m}$ depth $\left(11500 \mathrm{~km}^{2}\right)$ representing $35 \%$ of the Tanzanian area of the lake. This depth range was estimated to contain $45 \%$ of the demersal fish biomass (mostly haplochromines) (Cordone and Kudhongania 1971, Kudhongania and Cordone 1974a). Demersal biomass estimates were calculated from average catch rates (kg/hr). For the Mwanza Gulf, Witte at al. (2012) estimated the demersal haplochromine biomass at $36 \%$ of the total haplochromine biomass in the water column, which we assume is representative of other parts of the lake. Reported catches from Tanzania (Kolding et al. 2005) were used to calculate annual harvest rates as $\mathrm{H}=\mathrm{C} / \mathrm{B}$, where $\mathrm{C}$ is catch (ton/yr) and $\mathrm{B}$ is biomass (ton) and fishing mortality, $\mathrm{F}=-\ln (1-\mathrm{H}) / \mathrm{yr}$ (Haddon 2011) . To estimate the exploitation ratio $(E=C / P)$, where $P$ is production (ton/yr), a conservative $P / B$ ratio of 1.4 /yr was used (Moreau 1995) (See Appendix D). To induce the switch in the size-spectrum model the haplochromine model population was subjected to an additional mortality $F$ which was converted to an equivalent estimate of the total catch required to attain this mortality by $C=B .\left(1-e^{-F}\right)$ (Haddon 2011).

Size-based model

To examine the depensation hypotheses we use the size-spectrum model of Law et al. (2014) (see Appendix E for model equations), parameterized to represent the introduced Nile perch and a resident species with a haplochromine-like life history. The model is not intended to capture the dynamics of the haplochromine assemblage in Lake Victoria with its extremely diverse range of feeding behaviours and habitat specialisations (Greenwood 1974; Seehausen 1996; Witte and van 
Oijen 1990). Instead, we use a simplified model to investigate the possible outcomes when a resident and an introduced species interact.

A size-spectrum model is an appropriate tool to study depensation because it incorporates important size-dependencies between prey mortality, predator growth and recruitment, allowing predation to change as fish grow (Andersen and Beyer 2006; Benoît and Rochet 2004; Law et al. 2014). It can generate explicit predictions of population abundance and size-structure, which can be compared with empirical patterns. Stage-based processes emerge naturally from size-based processes, and thus are present in the much simpler size-structure. Another advantage is that the type of "control" that different size classes in the two populations exert on other size classes is an emergent feature of the model. Predator-prey interactions are assumed to be determined by relative body sizes only, thus predators are indifferent to the species identity of potential prey and target prey in a size range around a specified predator-prey body mass ratio. So, haplochromines of all sizes feed on other haplochromines, Nile perch and plankton provided they are the right size. Lastly, the number of parameters required is lower than other approaches, such as consumer-resource models (van de Wolfshaar et al. 2014) and physiologically structured models (Persson et al. 2007), and reliable estimates for these parameters are provided by general allometric rules.

The size-spectrum model has, at its core, a bookkeeping of biomass flow from prey to predator and from parent to offspring (Datta et al. 2010). Predators assimilate a fixed proportion of $20 \%$ of ingested prey biomass. Of the assimilated mass, a proportion $\varepsilon$ is allocated to somatic growth and the remaining proportion $1-\varepsilon$ to reproduction. The proportion $\varepsilon$ is a decreasing function of predator size $\mathrm{w}$, so that small individuals allocate all assimilated mass to somatic growth, while larger individuals allocate increased proportions to reproduction. The size at which the function $\varepsilon(w)$ equals zero corresponds to the asymptotic size $w_{\infty}$ for that species. In addition to the two interacting species, there is a resource (plankton) spectrum consisting of objects up to a maximum of $0.02 \mathrm{~g}$ in size. The resource productivity (i.e. its turnover rate) is assumed to operate on a faster timescale 
than fish productivity, allowing us to make the simplifying assumption that the resource spectrum is fixed, though the availability of the resource to a given fish species can be modified through an interaction coefficient $\theta$ (see Appendix E). The model is non-spatial and assumes that the community is well mixed. To examine, conceptually, the effects of dispersal of Nile perch from a single part of the lake we devised a two patch model with dispersal where modelled populations each independently have the same governing dynamics as in the size-spectrum model, and with net migration between them.

To represent the life-history of a generalized haplochromine species, we set the egg size at $0.01 \mathrm{~g}$, the mass at $50 \%$ maturity at $6 \mathrm{~g}$ and the asymptotic mass at $30 \mathrm{~g}$. This corresponds to a species that is planktivorous in its early life stages, switching gradually to piscivory in adulthood. To incorporate the mouth-brooding behavior of haplochromines, we assume that individuals of this species smaller than $0.05 \mathrm{~g}$ (Appendix C) are protected from predation by mouth brooding, but feed and grow normally. To represent Nile perch, we estimated the egg size as $0.001 \mathrm{~g}$ (corresponding with the 1.2 mm diameter of the egg, Hopson 1969), the size at 50\% maturity as $4.4 \mathrm{~kg}$ and the asymptotic size as $60 \mathrm{~kg}$. The mean predator-prey body mass ratio (PPMR) for the haplochromine-like species was estimated at 150 and for Nile perch as 300 . Table 2 shows all parameters and values used in the sizespectrum model.

The size-based model is used to address four specific questions: (1) is stable co-existence possible; if so is it likely that (2) fishing alone (3) predation or (4) limnological changes weakened depensation enough to initiate the Nile perch upsurge. Furthermore the impact of the Nile perch fishery starting at the switch is examined by applying a fishing mortality $F=0.5$ to Nile perch $>40 \mathrm{~cm}$.

Results

\section{Empirical observations}

Limnological changes in Lake Victoria 1920 to 2000 
Relatively rapid changes observed in sediment cores (Hecky et al. 2010) along with a shift in

meteorological conditions imply that a rapid change to a more eutrophic condition occurred abruptly just prior to and during the Nile perch upsurge. Eutrophication in Lake Victoria as a result of landbased processes has progressed over the last century (Hecky et al. 2010, Figure 3). The phosphorous (P) loading has increased in nearshore regions since the 1940s in synchrony with human population growth with ensuing deforestation, agriculture and urbanisation (Kolding et al. 2008; Verschuren et al. 2002). In offshore regions, a rapid change after the early 1980s (Figure 3B) was a result of changing oxygen conditions in the lake (Hecky et al. 2010). A steady decline in oxygen concentrations has been observed offshore starting around 1960 and between the late 1970s and early 1980s waters below 40 m suffered prolonged anoxia (Hecky et al. 1994; Verschuren et al. 2002). Based on time series of meteorological data, we infer that the change was caused by increased stratification caused by prolonged low wind stress starting around 1975 and exacerbated by an El Niño event in 1983 (Kolding et al. 2008; Maclntyre 2013; Maclntyre et al. 2014) (Figure 3A). Those conditions set the stage for limited vertical mixing, causing a larger anoxic volume in the deeper waters and a substantial increase in the availability of $\mathrm{P}$ liberated from internal sedimentary sources. Upon mixing in the water column, this additional internal loading resulted in enhanced phytoplankton bloom conditions (Cózar et al. 2012) .

The primary productivity record shows stable values from 1920 until 1940 and then a steady increase since 1940 up to the late 1980s in offshore sediments (Figure 3C). The nearshore primary production was variable until 1975, when a substantial increase in $\delta^{13} \mathrm{C}$ took place. By 1985 both nearshore and offshore $\delta^{13} \mathrm{C}$ stabilized or were still increasing at levels approximately $3 \%$ higher than in the 1940s. Productivity in Lake Victoria is nitrogen deficient (Talling 1966): much of the increased productivity was probably accomplished by $\mathrm{N}$-fixing cyanobacteria. As TP concentrations rose rapidly in sediments after $1980, \mathrm{~N}$ concentrations did not keep pace and $\mathrm{N}: \mathrm{P}$ ratios steadily decreased until 1982 when it suddenly dropped precipitously as P increased (Figure 3D). The decline in the $\mathrm{N}: \mathrm{P}$ ratio caused a concomitant shift in algal community composition from diatom and 
chlorophyte dominance the 1960s to cyanobacteria (Kling et al. 2001) around the time of the Nile perch surge, exacerbated probably by the increased anoxia in deeper waters of the lake. Anoxia would favour increased denitrification which maintained $\mathrm{N}$ deficiency in the lake.

Increased diatom microfossils (Hecky 1993) indicate that increased diatom productivity initially preceded the changes in $\mathrm{P}$ loading (Figure 3D). In addition to the subsequent shift to cyanobacteria, a shift to smaller diatom species that were more efficient in growing on low dissolved Si concentrations occurred as increased productivity depleted silica in the lake (Hecky 1993, Verschuren et al. 2002). This is consistent with the stratigraphic record that shows a drop in Aulacoseira spp. valve concentrations indicating a shift from the large heavily silicified Aulacoseira to the smaller species from 1977 (nearshore) and 1982 (offshore) onwards (Kling et al. 2001; Verschuren et al. 2002), just prior to and during the start of Nile perch takeover. Quiescent winds, waters with lowered temperatures, limited mixing and anoxic conditions in the decade after 1975 can explain the rapid loss of the heavy, fast sinking Aulacoseira that was most abundant in deeper waters (Stager et al. 2009).

Zooplankton communities were equally affected by eutrophication. Starting prior to the Nile perch takeover, nearshore Cladocera fossils (primarily Bosminidae) slowly decreased till 1985, followed by a sharp decrease. This decline was already well underway before the disappearance of demersal zooplanktivorous haplochromines that were replaced by the pelagic zooplanktivorous Rastrineobola (in Tanzania from 1984 onwards) and small $(<5 \mathrm{~cm})$ Nile perch. The combined biomasses of these two zooplankton eaters were lower than the zooplanktivorous haplochromine biomasses prior to the shift (Wanink et al. 2002). The decline in small cladocerans inshore may be a result of the change to filamentous and colonial cyanobacteria (Kling et al. 2001; Wanink et al. 2002). It may also be a result of changing inshore oxygen conditions permitting Chaoborus, a hypoxia tolerant zooplanktivorous insect, to become more abundant inshore, as indicated by their increased remains in sediment cores (Bridgeman 2001). In summary, the limno-chemical changes and changes 
at the low trophic levels were as dramatic and profound as the haplochromine collapse, and were all well underway prior to the shift to Nile perch (Figure 3E,F).

Changes in densities of Nile perch and haplochromines

From 1969 onwards in Tanzania Nile perch were present in trawl surveys with stable average densities of around $1 \mathrm{~kg} / \mathrm{hr}$ between 1974 and 1979. By 1983, overall densities had increased tenfold followed by another order of magnitude jump in 1984 (Figure 4). The rate of increase then slowed down until relative densities reached an average of around $120 \mathrm{~kg} / \mathrm{hr}(\mathrm{CV}=32 \%)$ over the next decade. In Uganda, Nile perch density was 200 times that in Tanzania in 1969/71 and still 20 times higher in 1981 to 1983. Original data no longer exist for the period between 1971 and 1981, but in 1981 experimental catch rates were twice as high as in 1971. After 1982 densities started increasing from around $10 \mathrm{~kg} / \mathrm{hr}$ to a long-term average of around $70 \mathrm{~kg} / \mathrm{hr}(\mathrm{CV}=35 \%)$ over the next two decades.

Meanwhile, the haplochromine biomass increased both in Uganda and Tanzania during the early 1970s. In Uganda, haplochromine biomass doubled between 1971 and 1984, after which it decreased. In Tanzania, haplochromine biomass peaked at $1900 \mathrm{~kg} / \mathrm{hr}$ around 1974 and then decreased to $600 \mathrm{~kg} / \mathrm{hr}$ in 1982, just before the start of the switch in Tanzania in 1983 (Goudswaard et al. 2008). From 1983 until the collapse in 1985, haplochromine biomass fluctuated between 314 and $785 \mathrm{~kg} / \mathrm{hr}$ (Figure 4). The lowest average biomass levels were $0.7 \mathrm{~kg} / \mathrm{hr}$ in Tanzania (1988) and $0.01 \mathrm{~kg} / \mathrm{hr}$ in Uganda (1993). Since then, haplochromine biomasses increased to between 100 and $250 \mathrm{~kg} / \mathrm{hr}$.

\section{Changes in size structure of Nile perch}

From the early 1960s until the upsurge, Nile perch had self-sustaining populations all over the Lake consisting mainly of adults $(\geq 70 \mathrm{~cm})$ and with only very low numbers of the smallest juvenile specimens, the recruits $(<15 \mathrm{~cm}$ ) (Figure 5). Between 1969 and 1975, median sizes of the few Nile 
perch caught in experimental surveys were $99 \mathrm{~cm}$ (range 43-106 cm, N=5) and $95 \mathrm{~cm}(34-158 \mathrm{~cm}$, $\mathrm{N}=53$ ) in Tanzania and Uganda respectively. The average size decreased between 1979 and early 1985, but large numbers of Nile perch recruits only appeared in Tanzania in the second half of 1985 and in Uganda perhaps as late as 1989. Since then, large numbers of Nile perch recruits have been present in all experimental trawl hauls irrespective of depth and location, with highest abundances in shallow inshore waters (Tumwebaze et al. 2002). This suggests that the early scarcity of Nile perch recruits was not a sampling artifact. Early reports of Nile perch catches refer to large mesh sizes only (Marten 1979; Scully 1976a, b), although small-meshed gillnets were used to catch haplochromines and would have caught Nile perch recruits if present (Cornelissen et al. 2015; Marten 1979). The immense recruitment potential of Nile perch therefore appeared very late during the Nile perch invasion. The rapid timing of the burst of recruits is clearly shown in the Tanzanian data set (Figure 6A): while between September 1984 to July 1985, no fish <6 g was caught, small recruits suddenly appeared between July and December 1985. In the course of a year, the Nile perch size spectrum developed from a highly right-skewed distribution to a flat, Sheldon-type distribution after the appearance of sub-adult Nile perch of around $30-40 \mathrm{~cm}$ (Figure 6A, arrow) between January and April 1985. This appearance cannot be explained by local population growth based on the available Nile perch adult biomass in the Mwanza Gulf. The flat distribution stabilizes over the following 15 years examined here. Similar developments in Nile perch size structure were seen in the Emin Pasha Gulf to the West of the Mwanza Gulf, while in the Kagera area recruitment was fully developed by 1985, before the Mwanza gulf (Goudswaard et al. 2008).

Nile perch spatial distribution: dispersion and patch density

Two processes need to be distinguished in the observations on the biomass increase of Nile perch since its introduction: dispersion over the lake, described by the encounter rates $\left(P_{c}\right)$, and density increase, described by the patch density $\left(\mathrm{CPUE}_{\mathrm{po}}\right)$. The changes of Nile perch encounter rates and patch densities over depth and time are well described by the thin-plate spline regression model, 
which is significant for all time-series examined (see Appendix D). However, there is a large variability in spatial distribution of Nile perch as the model explains only $10 \%$ to $40 \%$ of the deviance in encounter rate. Patch densities are equally variable as only $8 \%$ to $31 \%$ of the deviance is explained by depth and time. Both results highlight the large variability in experimental catches and the spatial heterogeneity in Nile perch abundances (Cornelissen et al. 2015; Taabu-Munyaho et al. 2013; TaabuMunyaho et al. 2014).

Following 1970, Nile perch encountered in experimental trawl hauls changed in terms of their size, from large adults to small recruits, in their depth distribution, from shallow to deep, and in their location, from northern parts of the lake to southern parts (Figure $7 A, B, C$ ). By 1969, in the shallow Ugandan part of the lake, adults $(\geq 70 \mathrm{~cm})$ were encountered already in $10 \%$ of the hauls, increasing to $35-40 \%$ in recent years. In Tanzania adult encounters started from low levels to $12-25 \%$ of the hauls at the start of the upsurge in 1983, peaked around 1990 and since decreased to levels comparable with Uganda. Sub-adult (between $\geq 15$ and $<70 \mathrm{~cm}$ ) encounter rates were very low prior to the start of the Nile perch boom, but increased rapidly to $90-95 \%$ of the hauls in Tanzanian shallow waters around the end of the 1980s, while in Uganda the sub-adult population development started later and peaked 5-7 years later. The upsurge in Nile perch recruits was more pronounced, more rapid and occurred later than the increase in adults and sub-adults. The start of the recruitment burst was both less concentrated in time and possibly later in Uganda compared to Tanzania. Loss of raw data in the crucial period between 1984 and 1988 may have obscured the precise timing, but no recruits were found by experimental fishing in 1984 while they were present in virtually all hauls from 1988 onwards. In both countries Nile perch encounter rates of all sizes were highest at $20 \mathrm{~m}$ depth and lowest at $45 \mathrm{~m}$ depth. Expansion into deeper waters is still ongoing for all size categories (Figure 7A,B,C).

Adult Nile perch was well established prior to the surge where it occurred: patch densities $\left(\mathrm{CPUE}_{\mathrm{po}}\right)$ in Uganda remained remarkably stable before and after the switch where it hovered 
between 4-8 kg/ha in 1969 and 7-10 kg/ha in 2011 (Figure 7D). In Tanzania adult patch density increased at all depths from 1969 onwards by around a factor $2-3$ to around $8 \mathrm{~kg} / \mathrm{ha}$ till the end of the 1990s, similar to Uganda. Sub-adult patch densities increased with different speeds in the two countries and depths but were around $14-16 \mathrm{~kg} / \mathrm{ha}$ by 2011 . Patch densities of recruits in shallow waters increased rapidly after 1985 but leveled off around 1995 in Uganda. The same level was reached in Tanzania 10 years later following a plateau between 1987 and 2000. In deeper waters recruitment levels still continue to increase but always around 4x higher in Tanzania than in Uganda. Surprisingly, in Tanzania patch biomass added over all sizes increased only by a factor 1.5 - 2 between 1975 and 1988. Since then it increased and leveled off at a factor 2.4-2.6 depending on depth between 2000 and 2011. In Uganda total patch biomass continues to increase (at least until 2011) without any signs of leveling off to a factor $1.4-1.8$ of the 1975 level.

The adult relative biomass ( $C P U E_{a d}$ ) highlights the different developments in the north and south. In Uganda the estimated adult biomass was initially 2.5 to 10 times higher than in Tanzania, increased by a factor 4-5 until it stabilized around 1983 with some fluctuations after the switch; in contrast adult relative biomass in Tanzania increased with a factor 50-100 until the early 1990-ies after which it stabilized or decreased to similar levels as in Uganda. In both areas and at all depths both sub-adult and recruit relative biomass continued to increase to level off in shallow waters only in recent years. In 2011 the total relative biomass over all sizes was still increasing in both the Ugandan and Tanzanian parts of the lake.

\section{Results of the size-spectrum model}

In the single-species size-spectrum model, a haplochromine-like species can successfully establish from a low density with only the resource spectrum as an initial food supply. In contrast, when run as a single-species model, Nile perch on its own cannot establish from low introduced densities. Instead, it requires a "trophic ladder" (Hartvig et al. 2011), i.e. a smaller resident species to provide a food source to allow juvenile Nile perch to grow to adulthood. In the two-species model, 
the introduction of a small population of large (between $4.4 \mathrm{~kg}$ and $12 \mathrm{~kg}$ ) adult Nile perch to an established resident haplochromine population leads to an initial expansion of the Nile perch population (Figure 8), after which the system settles down to co-existence. During co-existence, the haplochromine biomass is reduced to approximately $60 \%$ of the pre-invasion level and larger sized haplochromines (>18 g) almost disappear from the distribution (98\% decline). The total biomass of the resident species is around 3 times the Nile perch biomass, which is dominated by adults $(\geq 70 \mathrm{~cm})$ with relatively few juveniles $(<70 \mathrm{~cm})$ and a juvenile to adult biomass ratio of 0.2 .

To induce a switch from stable co-existence, an increased external mortality rate of $5 / \mathrm{yr}$ was applied to the adult (>6 gr) haplochromines. This caused a rapid decline and eventual collapse of the haplochromines and a simultaneous increase in juvenile Nile perch over the following 8-10 years (Figure 8,6B). During this period, the adult Nile perch biomass remains relatively unchanged, but the juvenile to adult biomass ratio increases from 0.2 to 2.4 . The predicted speed of the switch depends on the external mortality rate applied to the haplochromines: the higher the external mortality rate, the faster the switch. At a mortality rate of $5 / y r$, the duration of the switch is around 10 years. However, the minimum additional mortality rate on the adult haplochromines needed to cause the switch is around $4 / \mathrm{yr}$, while an overall mortality of $1 / \mathrm{yr}$ is sufficient if all size classes of the haplochromines are affected rather than just fish of $>6 \mathrm{~g}$. Applying a fishing mortality of $\mathrm{F}=0.5 / \mathrm{yr}$ to Nile perch $>40 \mathrm{~cm}$, starting simultaneously with the external mortality on haplochromines reduces the density of adult Nile perch, but otherwise doesn't have a major impact: the switch still takes place and almost as rapidly. However, we stress the point that the haplochromine 'collapse' is not an alternative stable state: removing the additional mortality before the haplochromine goes extinct results in a return to co-existence. So, the coexistence state is stable and the Nile perch only state is unstable. This means that, in a single patch, the Nile perch can never drive the haplochromines to complete collapse on its own. Adding dispersal between patches to the model does not change this prediction because dispersal can never stabilize the unstable Nile-perch only equilibrium (Appendix D). It is possible that dispersal could destabilize the coexistence state. This could lead to periodic 
solutions (similar to a predator-prey cycle), asymmetric solutions (e.g. large Nile perch population and small haplochromine population in one patch and vice versa the next) or more complex dynamics. However, without external mortality, it cannot lead to extirpation of the haplochromines in either patch.

\section{Confronting the size-spectrum model with the data}

\section{Size-spectrum model prediction 1: development of Nile perch and haplochromine biomass}

The size-spectrum model results broadly match with the survey observations during the late 1970s and early/mid 1980s, when the haplochromine collapse was accompanied by a rapid increase in numbers of juvenile Nile perch. Both in Tanzania and Uganda, there were few observations of juveniles prior to 1982 - hence the ratio is close to 0 (Figure 9A). After 1982, the juvenile to adult biomass ratios ranged on average from 0.3 to 8 in 2011 . The model ratio predictions on co-existence and Nile perch only states imply that in Tanzania the system became unstable between 1975/8 (20$45 \mathrm{~m}$ depth) and $1982(5 \mathrm{~m})$, and switched to an, on average, Nile perch only state in $1983(20 \mathrm{~m})$, 1985 (45 m) and 2000 (5 m) (Figure 9A). Correspondingly, in the Mwanza Gulf, the recruitment burst was observed in 1985 (Figure 6A,B). In Uganda the system became unstable around 1982 (5 m depth) and 1986 (>20 m), and the predicted ratio of juvenile to adult ratio of the Nile perch only state was reached on average in 1991, three years after the observed recruitment burst (Figure 9B). The observed duration of the development from co-existence to Nile-perch only was 7-10 (45-20 m), to 20 years $(5 \mathrm{~m})$ in Tanzania and between $7(5-20 \mathrm{~m})$ to 35 years $(45 \mathrm{~m})$ in Uganda (Figure 9A). The observed switch in much of the lake's waters therefore was faster than or as fast as predicted by the size-spectrum model using an external haplochromine adult mortality rate of $5 / \mathrm{yr}$. This suggests that in reality adult mortality rates of haplochromines would have been higher, or that mortality occurred over a wider size range of haplochromines simultaneously.

During co-existence in the size-spectrum model, total Nile perch biomass is about $0.22 \mathrm{~g} / \mathrm{m}^{3}$ and the haplochromine biomass is $0.67 \mathrm{~g} / \mathrm{m}^{3}$ corresponding to a haplochromine: Nile perch $(\mathrm{H} / \mathrm{L})$ 
biomass ratio of about 3. The observed pre-switch $\mathrm{H} / \mathrm{L}$ ratio was around 10 in Uganda and around 200 in Tanzania. In the Winam Gulf (Kenya), pre-switch H/L ratios were measured at 34 and 10 (Figure 9B). H/L ratios decreased in all countries and the predicted co-existence ratios were passed around 1979 (Kenya), 1983 (Uganda) and 1985 (Tanzania), coinciding with the appearance of Nile perch recruits $<15 \mathrm{~cm}$ in Kenya and Tanzania. Haplochromines nearly vanished shortly after the switch, but started increasing again from the early 1990s onwards (Figure 4). Presently, in waters less than $20 \mathrm{~m}$ depth in Tanzania, the $\mathrm{H} / \mathrm{L}$ ratio is back up to around 3 (Figure $9 \mathrm{~B}$ ).

\section{Size-spectrum model prediction 2: did fishing disturb co-existence?}

Fishing on haplochromines took place all over the lake in the 1970s (Marten 1979). Between 1969 and 1985, Tanzanian catch and biomass estimates result in back-calculated fishing mortalities of 0.04 $-0.31 / \mathrm{yr}$ (Table 3), much lower than the $4 / \mathrm{yr}$ required to induce the switch in the model. The average exploitation $(C / P)$ ratio was 0.09 , indicating that on average less than $10 \%$ of the annual demersal production was fished. These estimates do not take into account the $63 \%$ pelagic fraction of the haplochromine biomass (Witte et al. 2012), nor the unfished haplochromine biomass deeper than $30 \mathrm{~m}$. Between 1974 and 1982, the observed haplochromine demersal biomass decreased by 150,000 ton, which corresponds to a decrease of $61 \%$ of the productive capacity. Even if catch was underestimated, exploitation rates would need to be at least 5 times higher than reported to explain the observed decrease in demersal biomass.

According to Goudswaard (2008), the Nile perch upsurge started in the Winam Gulf, a $1400 \mathrm{~km}^{2}$ enclosed Gulf comprising $20 \%$ of the Kenyan area of the lake, followed by a migrating wave of subadult Nile perch that spread anti-clockwise around the lake and subsequently triggered switches as the wave hit new areas. This domino effect was thought to have been activated by a local decline in haplochromine biomass caused by fishing in the Winam Gulf (Goudswaard, 2008). Reported catches from Winam Gulf result in estimated fishing mortality rates of $0.15-0.46 / \mathrm{yr}$ and exploitation (C/P) ratios of $0.20-0.26$, much higher than in Tanzania, but still considerably lower than what is required 
to induce the switch in the model. In 1979 Nile perch recruitment had started (Goudswaard et al. 2008) and the $\mathrm{H} / \mathrm{L}$ ratio had dropped to 1.3 , well below the co-existence level predicted by the model (Figure 9B). Between 1977 and 1979 a decrease of $10 \mathrm{~kg} / \mathrm{ha}$ in demersal haplochromine biomass was observed (Table 3). To produce this decrease by fishing alone would have required a catch twice as high as the reported total catch of 3000 ton annually over the two years. Likewise a fishing mortality of $4 / \mathrm{yr}$ needed to induce a switch, would require a catch of 7300 ton/yr, around 2.7 times higher than the reported total haplochromine catch. Fishing pressure was relatively high and thus may have speeded up the observed haplochromine decline in the Winam Gulf, and it is indeed the first area in the lake where the Nile perch switch was observed. But fishing mortality alone was, according to our model, probably not high enough to produce the observed rapid local haplochromine biomass decrease needed to instigate the switch.

\section{Size-spectrum model prediction 3: did Nile perch predation disturb co-existence?}

Neither can the decrease in haplochromine biomass be attributed to an increase in Nile perch biomass. In Tanzania the strongest decrease in haplochromine biomass was between 1976 and 1979 when Nile perch stocks were still very low (Figure 4,7 ). Then the demersal relative biomass of haplochromines fluctuated around $550 \mathrm{~kg} / \mathrm{hr}(\mathrm{CV}=33 \%)$, just before the next rapid decrease when the Nile perch took over in 1985. By comparison, in Uganda, the haplochromine biomass initially increased after 1970 despite the much higher abundance of Nile perch over the whole pre-surge period. The decline started in 1981, and stocks collapsed after 1983. In the Winam gulf the 1977 Nile perch biomass estimate was $2.8 \mathrm{~kg} / \mathrm{ha}$ (Muller and Benda 1981) largely consisting of adults. Given a consumption ratio $\mathrm{Q} / \mathrm{B}=2.41 / \mathrm{yr}$ (Moreau 1995), the Nile perch would consume around $950 \mathrm{ton} / \mathrm{yr}$ corresponding to $6 \%$ of the total demersal and pelagic production of haplochromines, insufficient to produce a collapse.

Size-spectrum model prediction 4: did eutrophication disturb co-existence? 
While primary productivity doubled since 1962, algal biomass increased 4-10 fold (Hecky et al.

2010) and eutrophication also changed the size spectrum of phyto- and zooplankton (Jackson 2004; Yasindi and Taylor 2003) as well as water turbidity. Thus the available food resources to juvenile haplochromines and Nile perch may have changed. We modelled such a change by reducing the plankton abundance available to fish. Reducing the overall plankton resource in the size-spectrum model reduces the initial food supply equally for small haplochromines and Nile perch. This causes a drop in biomass for both, but, although the drop is larger for haplochromines, it will not instigate a Nile perch boom or a haplochromine collapse. If, however, the plankton availability is reduced for haplochromines, but maintained for Nile perch, then the switch does occur similar to the results shown (Figure 7). Thus, a reduction in those plankton resources available to haplochromines without a reduction in plankton resources available to Nile perch is a potential alternative mechanism to cause a switch.

\section{Discussion}

Two alternative hypotheses and associated mechanisms have been suggested to explain the demise of the haplochromines and takeover of the Lake Victoria fish assemblage by Nile perch: a trophic cascade instigated by Nile perch predation on haplochromines and released recruitment depensation. Before we discuss these hypotheses, we give a brief summary of the more remarkable features that have emerged from the observed trends in long term data series and the confrontation of model predictions with these observations: (1) the initial rapid lake wide expansion of large adult Nile perch from a small number of introduced sub-adults without any measureable amounts of recruits; (2) the two decades of relatively stable co-existence between adult Nile perch and haplochromines, which we suggest can be a result of intraguild, size-dependent, predation (Van de Wolfshaar et al. 2006); (3) the high level of external mortality of haplochromines that the sizespectrum model requires to induce a switch to a Nile perch dominated state; (4) the good correspondence between the predictions of the size-spectrum model with external mortality of 
haplochromines and the observed development in the demographic structure of the Nile perch stock; (5) the spatial developments of the Nile perch population in the lake, with continued expansion into the deep offshore waters, as well as continued increase in relative biomass, both indicating that the colonization of Lake Victoria by Nile perch is still not complete; and (6) the gradual recent return of the haplochromines to densities at predicted co-existence levels.

The most straightforward explanation of the Nile perch invasion is a simple trophic cascade (Downing et al. 2013). However, this hypothesis does not really fit with the observed demographic size structure and the sequence of biomass developments in both Nile perch and haplochromines. Between 1969 and 1980, the years where logistic growth was supposed to be in a log-linear phase, the observed Nile perch growth rates at different depths were in the range $0.29-0.37 / \mathrm{yr}$ in Tanzania and $0.15-0.18 / y r$ in Uganda, thus much lower than 0.73 /yr used in the logistic growth model (Figure 10B). In addition, Nile perch was fished almost immediately after its introduction putting constraints on the logistic growth (Figure 10A). The development in Nile perch catches may suggest an underlying logistic process in biomass development but is as dependent on a starting fishery. Early catch reports may not be reliable, but imply very high harvest rates $(\mathrm{H}=\mathrm{C} / \mathrm{B})$ prior to 1975 (Figure 10A). Lastly, under steady-state conditions, the observed resurgence of haplochromines does not conform to the mechanism behind logistic growth; Nile perch has not changed its prey preferences, its population is still increasing and by 2011 may even not have reached its carrying capacity (Figure 4,7). Thus several empirical observations contradict the hypothesis of a simple trophic cascade. Our analysis largely supports Goudswaard et al.'s (2008) description of the chronology and initiation of the Nile perch switch in Lake Victoria. But there are few data to support the hypothesis that a wave of sub-adult Nile perch originating in Kenya was sufficient to induce a cascading domino effect. The size-spectrum model predicts that, in a well-mixed lake, coexistence of Nile perch and a haplochromine-like species is stable. Conversely, the Nile-perch only state is unstable to the introduction of a small population of haplochromines. Including spatial heterogeneity and dispersal in the model would not change this key result. In particular, if the Nile perch density increased in a 
546 localised part of the lake for some reason, dispersal would eventually cause this area to revert to 547 coexistence, rather than to propagate the switch to adjacent areas of the lake. Hence, the switch in 548 the Winam Gulf (Kenya) would likely have remained a local affair were it not for the decrease in 549 stocks over most of the lake areas in the years prior to the lake-wide switch, still with low Nile perch 550 densities and no recruitment. Given the similar larval feeding habits of Nile perch and 551 haplochromines, but strikingly different early life history strategies, and absence of Nile perch 552 recruitment until after the surge, it is reasonable to assume that predator-prey interactions may have

553 been reciprocated and that depensation may have prevented a simple or locally induced cascade.

Although the two-species size-spectrum model gives a very simplified picture of the complex assemblage of haplochromines in Lake Victoria and their diverse range of adult feeding and habitat niches, it nevertheless suggests that stable co-existence was possible for the two first decades after introduction. During coexistence in our model, haplochromines had a depensatory effect on the Nile perch population, via strong predation on its miniscule and unprotected egg and fry stages, which would explain the empirically observed absence of juveniles. Co-existence through haplochromine predation on Nile perch was proposed by Walters and Kitchell (2001) and predicted from a consumer-resource model by van de Wolfshaar et al. (2014), who used a "foraging arena" approach to predator consumption. They assumed that at decreasing haplochromine densities, the more sheltered, and harder to catch species, e.g. rock cichlids, were the ones remaining. However, empirical data show that co-existence was not just between rock-dwelling species inaccessible to open water Nile perch, but existed in all habitats. For instance, during a 1995-96 acoustic survey in the Ugandan part of the lake, $84 \%$ of the pelagic fish biomass was haplochromines (Tumwebaze 1997). Based on our analysis, we propose that co-existence depends on size-related differences in early juvenile feeding and survival caused by mouth brooding of the haplochromines. This is another "foraging arena" but one that does not require a spatial separation of haplochromines with different vulnerabilities to predation: the functional response emerges directly from size-based predation processes and the behavior of haplochromines. Only when the haplochromines are subjected to 
572 additional external mortality, our model suggests, the control on the introduced Nile perch is

573 gradually lost with subsequent cascading collapse of the resident species and the appearance of Nile 574 perch recruits.

575

576

577

578

579

580

581

582

583

584

585

586

587

588
Expansion of Nile perch still takes place (Figure 7), but the observed gradual lake-wide population growth pattern of Nile perch is not predicted by the size-spectrum model as it has no spatial dimension and hence contains no information on dispersal processes. But co-existence takes place at the patch level: the observed developments in Nile perch patch densities and recruitment are reflected in the results of the size spectrum-model, indicating that co-existence between Nile perch and haplochromines is possible. Patch densities of adult Nile perch in Uganda were stable before and after the switch as predicted (Figure 7D). In Tanzania Nile perch arrived at least 7 years after the first introduction. Twenty years later, by the time of the switch, it had on average not yet reached the predicted co-existence levels. This implies that the development towards coexistence is slower than the $8-10$ years suggested by the model. Modelled total Nile perch biomass increased by a factor 1.9 (with fishing) to 2.6 (without) from pre-switch levels, which is close to the observed total patch biomass increase since 1975 in Tanzania and Uganda (factor 2.4-2.6 and 1.4-1.8 respectively). The model stabilizes within 10-13 years after the external mortality on haplochromines and between 15-20 years after the recruitment burst of 1985 as observed in Tanzania (Figure 8).

Species diversity aspects are ignored in the present analysis. The size-spectrum model collapses the formerly 500+ species rich haplochromine assemblage consisting of many stenotopic species with differing ecologies, into one generalized resident species with maximum size and large protected fry as main traits (Table 2). Loss of diversity, in particular the early loss of large piscivorous haplochromines (Witte et al. 1992), could have played a facilitating role in the Nile perch invasion. Nevertheless, haplochromine diversity is not needed in our model. Fry of most haplochromines start feeding on zooplankton and most of the trophic niche specialization emerges only later during ontogeny. Our model result then would imply that it is the total biomass of adult haplochromines 
that determines co-existence. The size spectrum model also predicts a loss of $98 \%$ of the largest haplochromines over $18 \mathrm{~g}$ during the first 10 years of co-existence. Hence, size specific predation, and possibly competition with Nile perch could result in loss of predatory haplochromine species diversity already during the stable co-existence phase. This may explain the observed early demise of many large piscivores among the cichlids (Witte et al. 1992). We cannot exclude the hypothesis that a decline in larger piscivorous haplochromines (Witte et al. 2007), rather than total haplochromine biomass, was sufficient to initiate the Nile perch upsurge. But then it remains to be explained why the burst took place 3-5 years after the observed decline of the large piscivores in all areas where adult Nile perch was present prior to the boom. No spatial effect of the haplochromine filter can be expected here as Nile perch recruits are encountered all over the lake - though more so in shallow waters - and many small adult sized piscivorous Haplochromine species existed as well just prior to the Nile perch recruitment burst.

External reduction of the haplochromines needed for disrupting co-existence in the model was larger than can be reasonably explained by fishing mortality alone. If so, then fishing on haplochromines was at most a proximate cause exacerbating the negative effects on already declining haplochromine stocks, but not sufficient on its own. Additional mortality may likely be sought in the changes associated with long term eutrophication, as first proposed by Hecky (1993). Our model suggests that a reduction in resource availability specific to haplochromines, but not affecting Nile perch is a potential alternative mechanism to increased haplochromine mortality. The concomitant fundamentally transformed zooplankton and phytoplankton assemblages altering the trophic base for the haplochromine assemblage, as well as increased hypoxia and decreased visibility for successful mating and feeding have been proposed as agents (Hecky et al. 1994; Hecky et al. 2010; Seehausen et al. 1997a; Seehausen et al. 2003). Theory predicts that loss of visibility impairs feeding efficiency of specialized predators, and predator populations would become less productive and/or less specialized (Seehausen et al. 2003). Both of these effects have been documented for Lake Victoria by Witte et al. (2013), who concluded that reduced water transparency had a negative 
impact on species coexistence through effects on both reproduction and feeding behaviour. After 1969, the Winam Gulf experienced a severe decline in transparency because of mineral turbidity from soil erosion which lead to an approximately $50 \%$ reduction in Secchi Disc transparency and a nearly proportional decline in primary productivity (Gikuma-Njuru et al. 2013) . From 1975, a decade of prolonged low windstress (Figure 3A) caused lake-wide shallower stratification (Maclntyre 2013) with ensuing blooms of cyanobacteria, resulting in increased anoxic volume, a decrease in large diatoms (Hecky et al. 2010) and a rapid decline in visibility in the mixed layer. Haplochromines were thus likely affected both by reduced visibility and reduced accessibility to plankton resources. The rapid decline in visibility in the mixed layer (Hecky et al. 2010; Mugidde 1993; Silsbe et al. 2006) coincided with the rapid decrease in haplochromine biomass as observed in Tanzania. Whether lowered visibility would affect Nile perch recruits similarly may be irrelevant as the decrease resulted in the release of the huge recruitment potential of Nile perch and sheer numbers would have resulted in the recruitment burst anyway. Moreover, unlike haplochromines, Nile perch eyes are equipped with a tapetum lucidum (Seehausen et al. 2003). In closely related Barramundi (Lates calcarifer) this structure develops already 10 days after hatching (size app. $5.6 \mathrm{~mm}$ ) allowing feeding under low light conditions (Yahaya et al. 2011). The ontogeny of the tapetum lucidum in Nile perch is not known, but if similar, it may lead to a competitive predatory advantage over like sized juvenile haplochromines.

Another aspect of eutrophication is the overall increased productivity of the lake (Kolding et al. 2008). Immediately after the surge of Nile perch a large fishery developed; catches rapidly increased and have been fluctuating around 240000 ton since 1987. Under steady state conditions the biomass would have been stable or decreasing. However, up until the end of the time series (2011) Nile perch biomass has continued to increase at all depths, but particularly in deeper waters. This indicates that primary and secondary productivity may have increased to sustain the catches (Kolding et al. 2008). But it also indicates that deeper waters have become more habitable for Nile perch, suggesting that effects of deoxygenation following stratification may now be less severe than 
during the switch phase. This is supported by a resumed wind stress and mixing since around 1990 (Figure 3A) (Cózar et al. 2012; Maclntyre 2013). Since 1998 no ENSO events have occurred to induce strong stratification, resulting in more benign oxygen conditions as well as increased visibility (Cornelissen et al. 2014; Maclntyre et al. 2014; Marshall et al. 2013).

The haplochromine stocks have also gradually increased again since the early 1990s and the haplochromine to Nile perch biomass ratio of 2011 is close to the predicted level of renewed coexistence (Figure 9B). In addition, if the proposed mechanism of depensation through a haplochromine fry predation filter is indeed operating, then a reversal to cichlid domination again is possible. If so, then both previous observations and our model predict a strongly reduced Nile perch recruitment, and a strong decrease in the adult stock that would severely affect the lucrative Nile perch fishery. However, while pre-biomass ratios have almost restored, neither juvenile:adult Nile perch ratios nor recruitment levels of Nile perch have decreased, and the predicted consequences of the reversal have not - yet? - occurred. The current haplochromine species assemblage also has little resemblance to the pre-switch stage, as it consists primarily of demersal and pelagic taxa that used to feed on detritus and zooplankton before their near-extirpation but some of which now feed on a mixed diet with benthic macro invertebrates (Downing et al. 2014). None of the pelagic and bathypelagic piscivore species shows any sign of recovering, except a pelagic species, now in a dwarf form that may not feed on fish but probably on zooplankton (Seehausen pers. obs.). Given that the new haplochromine assemblage appears better adapted to the effects of eutrophication (Witte et al. 2013, Witte et al. 2008) as well as to Nile perch predation, a stable co-existence between haplochromines and, perhaps, a reduced Nile perch stock may become likely. Haplochromines and Lates species coexist in other African Great Lakes as well, and so the Nile perch outburst in Lake Victoria, possibly a consequence of the haplochromine demise, was perhaps an anomaly. Nevertheless, eutrophication of the lake has continued unabated and the precarious climate conditions of low windstress and decreased mixing that likely contributed to the fundamental change 
674

675

676

677

678

679

680

681

682

683

684

685

686

687

688

689

690

691

692

693

694

695

in the in 1980s may again return. Lake Victoria has, during the last century, gone through dramatic, unprecedented and unexpected changes and may yet surprise us again.

\section{Acknowledgement}

In memory of Rosemary Lowe-McConnell and Frans Witte whose work on African inland waters and Lake Victoria in particular continues to inspire. Many thanks to Kees Goudswaard for the discussions and data provided. The LVFO, NAFIRRI and TAFIRI have provided us with the experimental fisheries data. We are grateful to Oliva Mkumbo for the discussions over the past years. Richard Law critically followed the development of the argument in the paper and his incisive questions and proposals for edits greatly improved its structure and content. We thank two anonymous reviewers and the theme editors for their generous and constructive comments. Andreas Taverna (Eawag) took the photos of cichlid fry. Martine Maan provided photographs of Pundamilia sp. hybrid fry. Audrie Siahanenia constructed the depth map of Lake Victoria. The contribution by Paul van Zwieten is part of the integrated project "Exploitation or eutrophication as threats for fisheries? Disentangling social and ecological drivers of ecosystem changes in Lake Victoria (SEDEC)," supported by the Netherlands Organisation for Scientific Research (NWO/WOTRO) grant number W01.65.304.00.

\section{References}

Andersen, K.H., and Beyer, J.E. 2006. Asymptotic Size Determines Species Abundance in the Marine Size Spectrum. The American Naturalist 168(1): 54-61.

Anderson, A.M. 1961. Further observations concerning the proposed introduction of Nile perch into Lake Victoria. East African Agricultural and Forestry Journal 26: 195 - 201.

Balirwa, J.S., Chapman, C.A., Chapman, L.J., Cowx, I.G., Geheb, K.I.M., Kaufman, L.E.S., LoweMcConnell, R.H., Seehausen, O.L.E., Wanink, J.H., Welcomme, R.L., and Witte, F. 2003. Biodiversity 
696

697

698

699

700

701

702

703

704

705

706

707

708

709

710

711

712

713

714

715

716

and Fishery Sustainability in the Lake Victoria Basin: An Unexpected Marriage? BioScience 53(8): 703-

716.

Barel, C.D.N., Dorit, R., Greenwood, P.H., Fryer, G., Hughes, N., Jackson, P.B.N., Kawanabe, H., Lowe-

McConnell, R.H., Nagoshi, M., Ribbink, A.J., Trewavas, E., Witte, F., and Yamaoka, K. 1985.

Destruction of fisheries in Africa's lakes. Nature 315(6014): 19.

Benoît, E., and Rochet, M.-J. 2004. A continuous model of biomass size spectra governed by

predation and the effects of fishing on them. J. Theor. Biol. 226(1): 9-21.

Bergstrand, E., and Cordone, A.J. 1971. Exploratory bottom trawling in Lake Victoria. African Journal of Tropical Hydrobiology and Fisheries (Kenya) 1(1): 13 - 23.

Beyer, J.E. 1987. On length-weight relationships. Part I: Computing the mean weight of the fish in a given length class. Fishbyte April 11 - 13.

Boggs, C.L., Holdren, C.E., Kulahci, I.G., Bonebrake, T.C., Inouye, B.D., Fay, J.P., McMillan, A.N.N., Williams, E.H., and Ehrlich, P.R. 2006. Delayed population explosion of an introduced butterfly. J. Anim. Ecol. 75(2): 466-475.

Bridgeman, T.B. 2001. The ecology and paleolimnology of food web changes in Lake Victoria, East Africa, University of Michigan, Ann Arbor MI, USA.

Cheung, W.W.L., Lam, V.W.Y., Sarmiento, J.L., Kearney, K., Watson, R., and Pauly, D. 2009. Projecting global marine biodiversity impacts under climate change scenarios. Fish and Fisheries 10(3): 235-251.

Cordone, A.J., and Kudhongania, A. 1971. Observations on the influences of codend mesh size on bottom trawl catches in Lake Victoria, with emphasis on the Haplochromis population pages. African Journal of Tropical Hydrobiology and Fisheries 1(2): 1 - 19. 
Cornelissen, I.J.M., Silsbe, G.M., Verreth, J.A.J., van Donk, E., and Nagelkerke, L.A.J. 2014. Dynamics and limitations of phytoplankton biomass along a gradient in Mwanza Gulf, southern Lake Victoria (Tanzania). Freshwater Biology 59(1): 127-141.

Cornelissen, I.J.M., van Zwieten, P.A.M., Peter, H.K., and Nagelkerke, L.A.J. 2015. Nile perch distribution in south-east Lake Victoria is more strongly driven by abiotic factors, than by prey densities. Hydrobiologia 755(1): 239-255.

Cózar, A., Bruno, M., Bergamino, N., Úbeda, B., Bracchini, L., Dattilo, A.M., and Loiselle, S.A. 2012. Basin-Scale Control on the Phytoplankton Biomass in Lake Victoria, Africa. PLoS ONE 7(1): e29962.

Datta, S., Delius, G., and Law, R. 2010. A Jump-Growth Model for Predator-Prey Dynamics: Derivation and Application to Marine Ecosystems. Bull. Math. Biol. 72(6): 1361-1382.

Downing, A., Galic, N., Goudswaard, K., van Nes, E., Scheffer, M., Witte, F., and Mooij, W.M. 2013. Was Lates Late? A Null Model for the Nile Perch Boom in Lake Victoria. . PLoS ONE 8(10): e76847.

Downing, A.S., van Nes, E.H., Balirwa, J.S., Beuving, J., Bwathondi, P.O.J., Chapman, L.J., Cornelissen, I.J.M., Cowx, I.G., Goudswaard, K.P.C., Hecky, R.E., Janse, J.H., Janssen, A.B.G., Kaufman, L., KisheMachumu, M.A., Kolding, J., Ligtvoet, W., Mbabazi, D., Medard, M., Mkumbo, O.C., Mlaponi, E., Munyaho, A.T., Nagelkerke, L.A.J., Ogutu-Ohwayo, R., Ojwang, W.O., Peter, H.K., Schindler, D.E., Seehausen, O., Sharpe, D., Silsbe, G.M., Sitoki, L., Tumwebaze, R., Tweddle, D., van de Wolfshaar, K.E., van Dijk, H., van Donk, E., van Rijssel, J.C., van Zwieten, P.A.M., Wanink, J., Witte, F., and Mooij, W.M. 2014. Coupled human and natural system dynamics as key to the sustainability of Lake Victoria's ecosystem services. Ecology and Society 19(4 C7 - 31).

Duponchelle, F., Ribbink, A.J., and (eds.). 2000. Fish Ecology Report. Lake Malawi/Nyasa/Niassa Biodiversity Conservation Project. SADC/GEF (Southern African Development Community, Gaborone, Botswana / Global Environmental Facility, Washington, D.C.). 
740

741

742

743

744

745

746

747

748

749

750

751

752

753

754

755

756

757

758

759

760

EAF/LVFO. 2013. Revised Nile Perch fishery management plan (NPFMP2) for Lake Victoria: years

2014 - 2019. SOFRECO, ACP Fish II programme, East African Community.

Everson, I., Taabu-Munyaho, A., and Kayanda, R. 2013. Acoustic estimates of commercial fish species in Lake Victoria: Moving towards ecosystem-based fisheries management. Fish. Res. 139: 65 - 75.

Fryer, G. 1960. Concerning the proposed Introduction of Nile perch into Lake Victoria. East African Agricultural Journal 25: 267-270.

García-Berthou, E. 2007. The characteristics of invasive fishes: what has been learned so far? J. Fish

Biol. 71: 33-55.

Gikuma-Njuru, P., Guildford, S.J., Hecky, R.E., and Kling, H.J. 2013. Strong spatial differentiation of N and P deficiency, primary productivity and community composition between Nyanza Gulf and Lake Victoria (Kenya, East Africa) and the implications for nutrient management. Freshwater Biology 58(11): 2237-2252.

Goudswaard, P.C. 2006. Causes and effects of the Lake Victoria ecological revolution. PhD, Faculty of Mathematics and Naturals Sciences and those of Medicine, Leiden University, Leiden.

Goudswaard, P.C., Witte, F., and Katunzi, E.F.B. 2008. The invasion of an introduced predator, Nile perch (Lates niloticus L.) in Lake Victoria (East Africa): chronology and causes. Env. Biol. Fish. 81: 127 139.

Goudswaard, P.C., Witte, F., and Wanink, J.H. 2006. The shrimp Caridina nilotica in Lake Victoria (East Africa), before and after the Nile perch increase. Hydrobiologia 563: 31 - 34.

Greenwood, P.H. 1974. Cichlid fishes of Lake Victoria, East Africa: the biology and evolution of a species flock. John Wright and Sons Ltd., Stonebridge Press, Bristol, UK. 
761

762

763

764

765

766

767

768

769

770

771

772

773

774

775

776

777

778

779

780

781

782

Haddon, M. 2011. Modelling and quantitative methods in fisheries. CRC Press, Taylor \& Frances Group, Boca Raton, US.

Hartvig, M., Andersen, K.H., and Beyer, J.E. 2011. Food web framework for size-structured populations. J. Theor. Biol. 272: 113 - 122.

Hecky, R.E. 1993. The eutrophication of Lake Victoria. Verhandlungen des Internat. Verein. Limnol. 25: $39-48$.

Hecky, R.E., Bugenyi, F.W.B., Ochumba, P., Talling, J.F., Mugidde, R., Gophen, M., and Kaufman, L. 1994. Deoxygenation of the Deep Water of Lake Victoria, East Africa. Limnol. Oceanogr. 39(6): 1476.

Hecky, R.E., Mugidde, R., Ramlal, P.S., Talbot, M.R., and Kling, G.W. 2010. Multiple stressors cause rapid ecosystem change in Lake Victoria. Freshwater Biology 55: 19-42.

Hopson, A.J. 1969. A description of the pelagic embryos and larval stages of Lates niloticus (L.)

(Pisces : Centropomidae) from Lake Chad, with a review of early development in lower percoid fishes. Zoological Journal of the Linnean Society 48(1): 117-134.

Jackson, V.S. 2004. The production and fate of picoplankton and protozoa in the pelagic food web of Napoleon Gulf, Lake Victoria, East Africa, University of Waterloo, Waterloo, Ontario, Canada.

Kalnay, E., Kanamitsu, M., R.Kistler, Collins, W., D.Deaven, Gandin, L., Iredell, M., Saha, S., White, G., Woollen, J., Zhu, Y., Chelliah, M., Ebisuzaki, W., Higgins, W., Janowiak, J., Mo, K.C., Ropelewski, C., Wang, J., Leetmaa, A., Reynolds, R., Jenne, R., and D.Joseph. 1996. The NCEP/NCAR 40-year reanalysis project. Bull. Am. Met. Soc. 77: 437 - 471.

Kanamitsu, M., Ebisuzaki, W., Woollen, J., Yang, S.-K., Hnilo, J.J., Fiorino, M., and Potter, G.L. 2002.

NCEP-DEO AMIP-II Reanalysis (R-2). Bulletin of the Atmospheric and Meteorologiocal Society 83(1631 - 1643). 
Kling, H.J., Mugidde, R., and Hecky, R.E. 2001. Recent changes in the phytoplankton community of Lake Victoria in response to eutrophication. In Great Lakes of the World: food webs, health and integrity. Edited by M. Munawar and R.E. Hecky. Backhuys, Leiden, the Netherlands. pp. 47 - 66.

Kolding, J., Medard, M., Mkumbo, O., and van Zwieten, P.A.M. 2013. Status, trends and management of the Lake Victoria Fisheries. In Inland fisheries evolution and management - case studies from four continents. Edited by R.L. Welcomme, J. Valbo-Jorgensen and A.S. Halls. Food and Agriculture Organisation of the UN, Rome, Italy.

Kolding, J., van Zwieten, P.A.M., Manyala, J., Okedi, J., Mgaya, Y.D., and Orach-Meza, F. 2005. Lake Victoria Environmental Management Program (LVEMP): Regional Synthesis Report on Fisheries Research and Management. States, trends and processes. Final report prepared for LVEMP National Secretariat. Lake Victoria Environmental Management Program, Entebbe, Uganda.

Kolding, J., van Zwieten, P.A.M., Mkumbo, O., Silsbe, G., and Hecky, R.E. 2008. Are the Lake Victoria Fisheries Threatened by Exploitation or Eutrophication? Towards an Ecosystem-based Approach to Management. In The Ecosystem Approach to Fisheries. Edited by G. Bianchi and H.R. Skjoldal. CAB International, Rome. pp. 309 - 354

Kudhongania, A.W., and Cordone, A.J. 1974a. Batho-spatial distribution pattern and biomass estimate of the major demersal fishes in Lake Victoria. African Journal of Tropical Hydrobiology and Fisheries 3: 15 - 31.

Kudhongania, A.W., and Cordone, A.J. 1974b. Past trends, present stock and possible future state of the fisheries of the Tanzanian part of Lake Victoria. African Journal of Tropical Hydrobiology and Fisheries 3: 167 - 181.

Law, R., Plank, M.J., and Kolding, J. 2014. Balanced exploitation and coexistence of interacting, sizestructured, fish species. Fish and Fisheries. 
MacIntyre, S. 2013. Climatic variability, mixing dynamics, and ecological consequences in the African great lakes. In Climatic Change and Global Warming of Inland Waters: Impacts and Mitigation for Ecosystems and Societies, First Edition. Edited by C.R. Goldman, M. Kumagai and R.D. Robarts. John Wiley \& Sons Ltd. pp. 311 - 336.

MacIntyre, S., Romero, J.R., Silsbe, G.M., and Emery, B.M. 2014. Stratification and horizontal exchange in Lake Victoria, East Africa. Limnology and Oceanography [Limnol Oceanogr] 59(5): 34.

Marshall, B.E., Ezekiel, C.N., Gichuki, J., Mkumbo, O.C., Sitoki, L., and Wanda, F. 2013. Has climate change disrupted stratification patterns in Lake Victoria, East Africa? African Journal of Aquatic Science 38(3): 249-253.

Marten, G.G. 1979. Impact of Fishing on the Inshore Fishery of lake Victoria (East Africa). J. Fish. Res. Bd Can. 36: 891 - 900.

Mkumbo, O.C., and Marshall, B.E. 2014. The Nile perch fishery of Lake Victoria: current status and management challenges. Fish. Manage. Ecol.: n/a-n/a.

Moreau, J. 1995. Analysis of species change in Lake Victoria using ECOPATH, a multispecies trophic model. In The Impact of Species Changes in African lakes. Edited by T.J. Pitcher and P.J. Hart.

Chapman and Hall, London. pp. 137 - 161.

Mugidde, R. 1993. The increase in phytoplankton primary productivity and biomass in Lake Victoria (Uganda). Verhandlungen des Internat. Verein. Limnol. 25: 846-849.

Muller, R.G., and Benda, R.S. 1981. Comparison of bottom trawl stock densities in the inner Kavirondo Gulf of Lake Victoria. J. Fish Biol. 19: 399 - 401.

Okaronon, J.O. 1999. The fish stocks of Lake Victoria. In Report on third Fisheries Data Working Group (FIDAWOG) workshop held at the Triangle Hotel, Jinja, 29 March to 1 April 1999. Edited by 
D.a.C. Tweddle, I.G. Fisheries Data Working Group of the Lake Victoria Fisheries Research Project, Jinja, Uganda. pp. 30-37.

Persson, L., Amundsen, P.-A., de Roos, A.M., Klemetsen, A., Knudsen, R., and Primicerio, R. 2007.

Culling prey promotes predator recovery - alternative stable states in a whole lake experiment. Science 316: 1743 - 1746.

Pringle, R.M. 2005. The origins of the Nile perch in Lake Victoria. BioScience 55(9): 780 - 787.

Sakai, A.K., Allendorf, F.W., Holt, J.S., Lodge, D.M., Molofsky, J., With, K.A., Baughman, S., Cabin, R.J., Cohen, J.E., Ellstrand, N.C., McCauley, D.E., O'Neil, P., Parker, I.M., Thompson, J.N., and Weller, S.G. 2001. The Population Biology of invasive species. Annu. Rev. Ecol. Syst. 32(1): 305-332.

Scully, R.J. 1976a. The importance of Furu (the haplochromine " species flock" ) in Lake Victoria's gill net fishery. Part I of a completion report on the passive gear fishery in the Tanzania waters of Lake Victoria. East African Freshwater Fisheries Research Organsiation (E.A.F.F.R.O.), Mwanza, Tanzania.

Scully, R.J. 1976b. Species composition estimates of commercial and experimental gillnet catches from the Tanzania waters of Lake Victoria (October 1973 - january 1975). Part II of a completion report on the passive gear fishery in the Tanzania waters of Lake Victoria. East African Freshwater Fisheries Research Organsiation (E.A.F.F.R.O.), Mwanza, Tanzania.

Seehausen, O. 1996. Lake Victoria rock cichlids: taxonomy, ecology and distribution. Verduyn cichlids. Seehausen, O., Alphen, J.J.M.v., and Witte, F. 1997a. Cichlid fish diversity threatened by eutrophication that curbs sexual selection. Science 277: 1808-1811.

Seehausen, O., van Alphen, J.J.M., and Witte, F. 2003. Implications of eutrophication for fish vision, behavioral ecology and species coexistence. In Conservation, Ecology, and Management of African 
849

850

851

852

853

854

855

856

857

858

859

860

861

862

863

864

865

866

867

868

Fresh Waters. Edited by T.L. Crisman, L.J. Chapman, C.A. Chapman and L.S. Kaufman. University Press of Florida, Gainesville, FL, USA.

Seehausen, O., Witte, F., Katunzi, E.F., Smits, J., and Bouton, N. 1997b. Patterns of the Remnant Cichlid Fauna in Southern Lake Victoria. Conservation Biology 11(4): 890-904.

Silsbe, G.M., Hecky, R.E., Guildford, S.J., and Mugidde, R. 2006. Variability of chlorophyll a and photosynthetic parameters in a nutrient-saturated tropical great lake. Limnol. Oceanogr. 51(5): 2052.

Stager, J.C., Hecky, R., Grzesik, D., Cumming, B., and Kling, H. 2009. Diatom evidence for the timing and causes of eutrophication in Lake Victoria, East Africa. Hydrobiologia 636(1): 463-478.

Taabu-Munyaho, A., Kayanda, R.J., Everson, I., Grabowski, T.B., and Marteinsdóttir, G. 2013.

Distribution and exploitation of Nile perch Lates niloticus in relation to stratification in Lake Victoria, East Africa. Journal of Great Lakes Research 39(3): 466-475.

Taabu-Munyaho, A., Nyamweya, C.S., Sitoki, L., Kayanda, R., Everson, I., and Marteinsdóttir, G. 2014. Spatial and temporal variation in the distribution and density of pelagic fish species in Lake Victoria, East Africa. Aquatic Ecosystem Health \& Management 17(1): 52-61.

Talling, J.F. 1966. The annual cycles of stratification and phytoplankton growth in Lake Victoria (East Africa). International Revue gesamten Hydrobiologie 50: 1 - 32.

Tsehaye, I., Machiels, M.A.M., and Nagelkerke, L.A.J. 2007. Rapid shifts in catch composition in the artisanal Red Sea reef fisheries of Eritrea. Fish. Res. 86(1): 58-68.

Tumwebaze, R. 1997. Application of hydroacoustics in fish stock assessment of Lake Victoria. MPhil thesis, University of Bergen, Bergen, Norway. 
869

870

871

872

873

874

875

876

877

878

879

880

881

882

883

884

885

886

887

888

889

Tumwebaze, R., Getabu, A., Bayona, MacLennan, D., and Cowx, I.G. 2002. Fisheries of Lake Victoria: an underwater perspective. In Management and Ecology of Lake and Reservoir Fisheries. Edited by I.G. Cowx. Fishing News Books, Blackwell Science, Oxford, UK. pp. 70-83.

van de Wolfshaar, K., HilleRisLambers, R., Goudswaard, K.C., Rijnsdorp, A., and Scheffer, M. 2014. Nile perch (Lates niloticus, L.) and cichlids (Haplochromis spp.) in Lake Victoria: could prey mortality promote invasion of its predator? Theor Ecol 7(3): 253-261.

Van de Wolfshaar, K.E., de Roos, A.M., and Persson, L. 2006. Size-dependent interactions inhibit coexistence in intraguild predation systems with life-history omnivory. The American Naturalist 168: $62-75$.

Verschuren, D., Johnson, T.C., Kling, H.J., Edgington, D.N., Leavitt, P.R., Brown, E.T., Talbot, M.R., and Hecky, R.E. 2002. History and timing of human impact on Lake Victoria, East Africa. Proceedings of the Royal Society London B: Biological Sciences 269: 289-294.

Walters, C., and Kitchell, J.F. 2001. Cultivation/depensation effects on juvenile survival and recruitment: implications for the theory of fishing Can. J. Fish. Aquat. Sci. 58(1): 39-50.

Wanink, J. 1999. Prospects for the fishery on the small pelagic Rastrineobola argentea in Lake Victoria. Hydrobiologia 407(0): 183-189.

Wanink, J.H., Katunzi, E.F.B., Goudswaard, K.P.C., Witte, F., and van Densen, W.L.T. 2002. The shift to smaller zooplankton in Lake Victoria cannot be attributed to the 'sardine' Rastrineobola argentea (Cyprinidae). Aquat. Living Resour. 15(1): 37-43.

Wanyala, B., and Marten, G. 1974. Survey of the Lake Victoria Fishery in Kenya. ANNUAL REPORT 1974. East African Freshwater Fisheries Research Organization, Jinja, Uganda. 
890

891

892

893

894

895

896

897

898

899

900

901

902

903

904

905

906

907

908

909

910

911

Welcomme, R.L. 1988. International introductions of inland aquatic species. FAO Fisheries Technical Paper. FAO, Rome, Italy.

Weyl, O.L.F., Booth, A.J., Mwakiyongo, K.R., and Mandere, D.S. 2005. Management recommendations for Copadichromis chrysonotus (Pisces: Cichlidae) in Lake Malombe, Malawi, based on per-recruit analysis. Fish. Res. 71(2): 165-173.

Witte, F., Goldschmidt, T., Wanink, J.H., Oijen, M.J.P.v., Goudswaard, P.C., Witte-Maas, E.L.M., and Bouton, N. 1992. The destruction of an endemic species flock: quantitative data on the decline of the haplochromine cichlids of Lake Victoria. Env. Biol. Fish. 34: 1-28.

Witte, F., Seehausen, O., Wanink, J., Kishe-Machumu, M., Rensing, M., and Goldschmidt, T. 2013.

Cichlid species diversity in naturally and anthropogenically turbid habitats of Lake Victoria, East Africa. Aquatic Sciences 75(2): 169-183.

Witte, F., Silsbe, G.M., Hecky, R.E., Goudswaard, P.C., Guildford, S.J., Kishe-Machumu, M.A., and Wanink, J.H. 2012. Did the loss of phytoplanktivorous fish contribute to algal blooms in the Mwanza Gulf of Lake Victoria? Hydrobiologia 679(1): 283-296.

Witte, F., and van Oijen, M.J.P. 1990. Taxonomy, ecology and fishery of Lake Victoria haplochromine trophic groups. Zoologische Verhandelingen 262: 1-47.

Witte, F., Wanink, J.H., Kishe-Machumu, M., Mkumbo, O.C., Goudswaard, P.C., and Seehausen, O. 2007. Differential decline and recovery of haplochromine trophic groups in the Mwanza Gulf of Lake Victoria. Aquatic Ecosystem Health \&amp; Management 10(4): 416 - 433.

Witte, F., Welten, M., Heemskerk, M., van der Stap, I., Ham, L., Rutjes, H., and Wanink, J. 2008. Major morphological changes in a Lake Victoria cichlid fish within two decades. Biological Journal of the Linnean Society 94(1): $41-52$. 
912 Witte, F., and Winter, W.d. 1995. Appendix II. Biology of the major fish species of Lake Victoria. In 913 Fish stocks and fisheries of Lake Victoria. A handbook for field observations. Edited by F. Witte and 914 W.L.T.V. Densen. Samara Publishing Limited, Dyfed, Great Britain. pp. 301-320.

915 Yahaya, S., Lim, L.-S., Shaleh, S.R.M., Mukai, Y., Anraku, K., and Kawamura, G. 2011. Ontogenetic eye 916 development and related behavioural changes in larvae and juveniles of barramundi Lates calcarifer 917 (Bloch). Marine and Freshwater Behaviour and Physiology 44(6): 339-348.

918 Yasindi, A.W., and Taylor, W.D. 2003. Abundance, Biomass and Estimated Production of Planktonic 919 Ciliates in Lakes Victoria and Malawi. Aquatic Ecosystem Health \& Management 6(3): 289 - 297. 


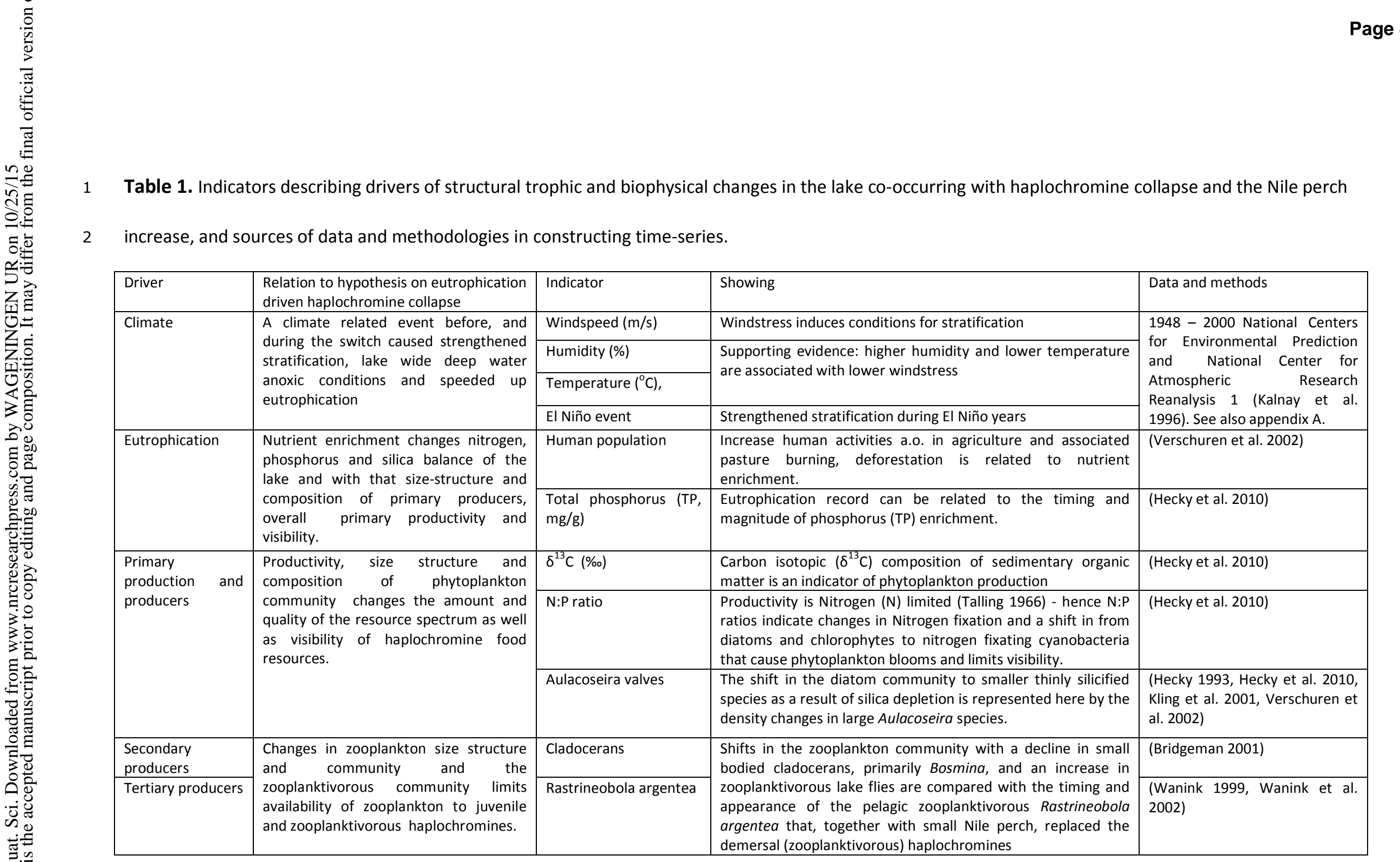


3 Table 2. Parameter values for the size-spectrum model.

Parameter Haplochromines Nile perch Units Comments

Fish life history

\begin{tabular}{lllll}
\hline$w_{0} e^{x_{0}}$ & 0.01 & 0.001 & $\mathrm{~g}$ & Mass of fish egg \\
$w_{0} e^{x_{l}}$ & 0.05 & 0.001 & $\mathrm{~g}$ & Minimum size subject to predation \\
$w_{0} e^{x_{m}}$ & 6 & 4400 & $\mathrm{~g}$ & Mass at $50 \%$ maturity \\
$w_{0} e^{x_{\infty}}$ & 30 & 60000 & $\mathrm{~g}$ & Asymptotic mass \\
$\rho$ & 0.2 & 0.2 & - & Exponent for reproduction function \\
$\rho_{m}$ & 10 & 10 & - & Measures width of transition from \\
& & & & immaturity to maturity
\end{tabular}

Dynamic size spectrum

\begin{tabular}{lllll}
\hline$K$ & 0.2 & 0.2 & - & Food conversion efficiency \\
$\alpha$ & 0.8 & 0.8 & - & Search rate scaling exponent \\
$A$ & 750 & 750 & $\mathrm{~m}^{3} \mathrm{yr}^{-1} \mathrm{~g}^{-\alpha}$ & Feeding rate constant \\
$\beta$ & 5 & 5.72 & - & Natural log of mean predator-prey \\
& & & & mass ratio \\
$\sigma$ & 2 & 2.2 & - & Measure of diet breadth \\
$\mu_{i, 0}$ & 0.1 & 0.1 & $\mathrm{yr}^{-1}$ & Intrinsic (non-predation) mortality \\
& & & & rate at size $w_{0}$ \\
$\xi_{i}$ & -0.2 & -0.2 & - & Exponent for intrinsic (non- \\
& & & & predation) mortality rate
\end{tabular}

Fixed plankton size spectrum

\begin{tabular}{llll}
\hline$w_{0} e^{x_{p, \max }}$ & 0.02 & $\mathrm{~g}$ & Maximum body mass of plankton \\
$u_{0, p}$ & 100 & $\mathrm{~m}^{-3}$ & Plankton density at $0.001 \mathrm{~g}$
\end{tabular}

$\begin{array}{llll}\gamma & 2 & - & \text { Exponent of plankton spectrum }\end{array}$

4

5 
6 Table 3. Haplochromine catch, biomass, catch over biomass (C/B) and catch over production (C/P) over selected years prior to the Nile perch switch.

$7 \quad \mathrm{~F}=$ fishing mortality=-In(1-C/B). Catch estimates from (Kolding et al. 2013, Kolding et al. 2005) except where indicated. Nile perch $\mathrm{Q} / \mathrm{B}=2.41 / \mathrm{yr}$ and

8 haplochromine $\mathrm{P} / \mathrm{B}=1 / 4 / \mathrm{yr}$ (Moreau 1995). CV=Coefficient of Variation.

\begin{tabular}{|c|c|c|c|c|c|c|c|c|c|}
\hline \multirow[t]{2}{*}{ Area } & \multirow[t]{2}{*}{ Year } & \multirow{2}{*}{$\begin{array}{l}\text { Catch } \\
\text { (ton/yr) } \\
\text { (CV\%) }\end{array}$} & \multicolumn{2}{|c|}{$\begin{array}{l}\text { Biomass haplochromines } \\
\text { (<30m depth) }\end{array}$} & \multirow{2}{*}{$\begin{array}{l}\text { C/B } \\
(\mathrm{F}) \\
(/ \mathrm{yr})\end{array}$} & \multirow[t]{2}{*}{$\begin{array}{l}\mathrm{C} / \mathrm{P} \\
(/ \mathrm{yr})\end{array}$} & \multirow{2}{*}{$\begin{array}{l}\text { Biomass } \\
\text { Nile perch } \\
\text { (kg/ha) } \\
\text { (ton) }\end{array}$} & \multirow{2}{*}{$\begin{array}{l}\text { Nile perch } \\
\text { consumption/ } \\
\text { Haplochromine } \\
\text { Production } \\
\text { (/yr) }\end{array}$} & \multirow[t]{2}{*}{ Assumptions } \\
\hline & & & $\begin{array}{l}\text { demersal } \\
\mathrm{kg} / \mathrm{ha}\end{array}$ & $\begin{array}{l}\text { total } \\
\text { ton (CV\%) }\end{array}$ & & & & & \\
\hline \multirow[t]{3}{*}{ Tanzania } & 1974 & 16624 & 361 & 416000 & $\begin{array}{l}0.04 \\
(0.04)\end{array}$ & 0.03 & & & \multirow{3}{*}{$\begin{array}{l}\text { 1)Haplochromine biomass excluding } \\
\text { biomass at depth } \geq 30 \mathrm{~m} \text { and pelagic } \\
\text { haplochromines, } 62 \% \text { of total biomass } \\
\text { (Witte et al. 2012) }\end{array}$} \\
\hline & 1980 & 20765 & 67 & 77000 & $\begin{array}{l}0.27 \\
(0.31)\end{array}$ & 0.17 & & & \\
\hline & $1974-1980$ & $\begin{array}{l}22000 \\
(30 \%)\end{array}$ & & $\begin{array}{l}180000 \\
(50 \%)\end{array}$ & $\begin{array}{l}0.14 \\
(0.15)\end{array}$ & 0.09 & & & \\
\hline \multirow[t]{4}{*}{$\begin{array}{l}\text { Kenya } \\
\text { (Winam gulf) }\end{array}$} & $1969 / 70 * * *$ & $\begin{array}{l}2700, \\
3800 *\end{array}$ & 35.8 & 13200 & $\begin{array}{l}0.20 \\
(0.23)\end{array}$ & 0.14 & & & \multirow{4}{*}{$\begin{array}{l}\text { 1) } 1500 \text { out of } 2000 \text { vessels were used in } \\
\text { haplo fishery* } \\
\text { 2) } 50 \% \text { total Kenya haplo biomass was } \\
\text { from the Winam gulf } \\
\text { 3) } 50 \% \text { Kenyan haplo catch was from } \\
\text { Winam gulf* } \\
\text { 3) Biomass includes pelagic } \\
\text { haplochromines, } 62 \% \text { of total biomass }\end{array}$} \\
\hline & 1975 & 2300 & 32.7 & 12055 & $\begin{array}{l}0.19 \\
(0.21)\end{array}$ & 0.14 & & & \\
\hline & $1977^{* * *}$ & 2700 & 28.4 & 10500 & $\begin{array}{l}0.26 \\
(0.30) \\
\end{array}$ & 0.18 & $2.8(400)$ & 0.06 & \\
\hline & $1979 * * * *$ & $3000 *$ & 18.4 & 6700 & $\begin{array}{l}0.49 \\
(0.67) \\
\end{array}$ & 0.49 & $\begin{array}{l}14.4 \\
(2000)\end{array}$ & 0.51 & \\
\hline
\end{tabular}




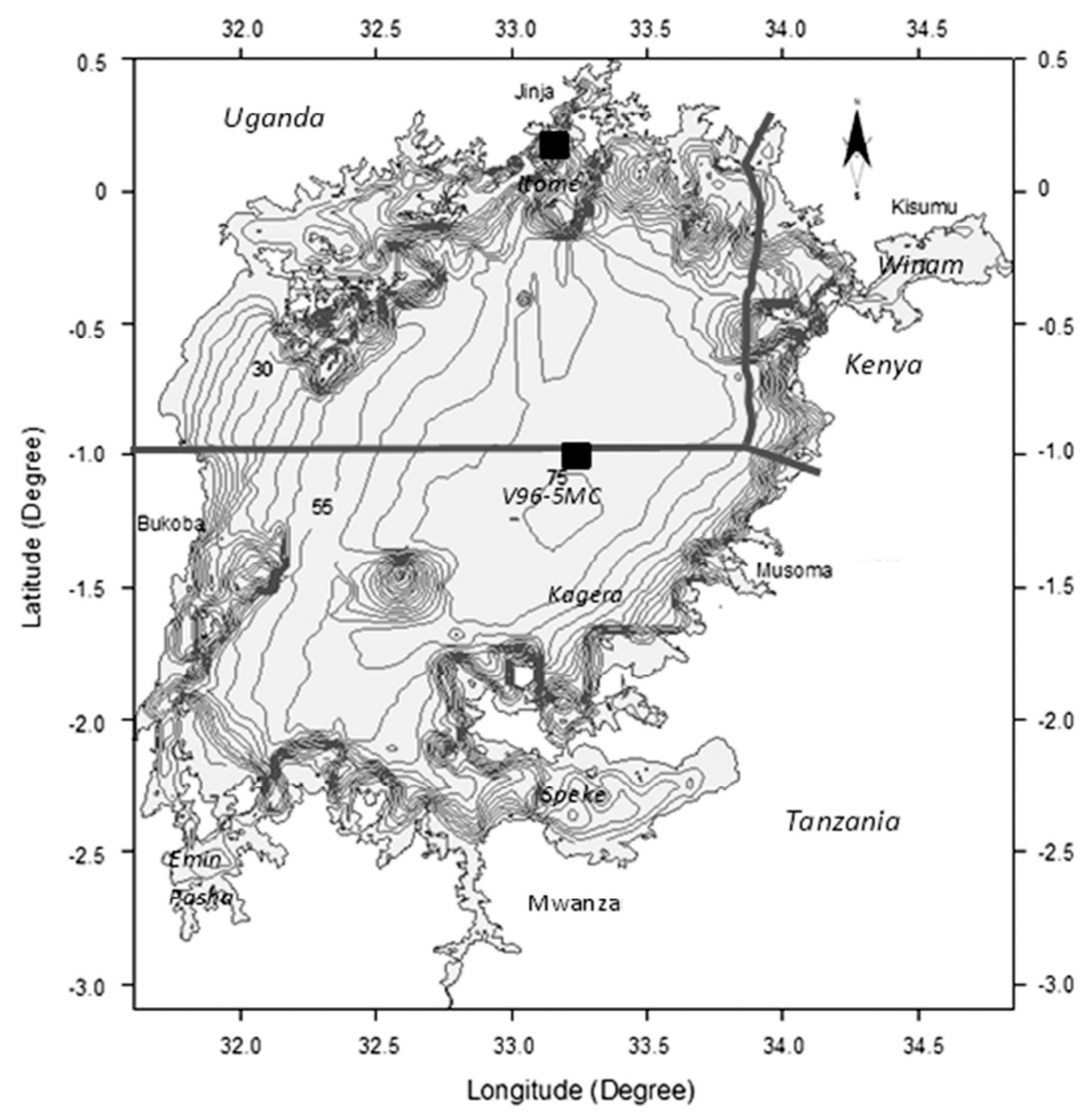

Figure 1. Map of Lake Victoria showing depth contours and main areas of the lake as discussed in the text. Black squares are the locations of two sediment cores Itome and V96-5MC (Hecky et al. 2010). $100 \times 101 \mathrm{~mm}(300 \times 300 \mathrm{DPI})$ 


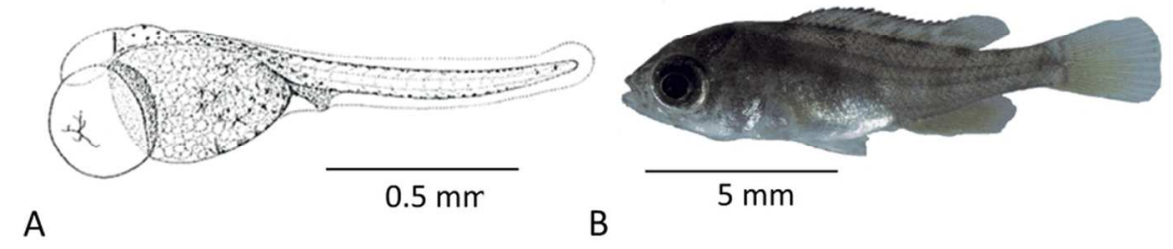

Figure 2. Comparison of sizes of (a) freeswimming Nile perch fry, $1.9 \mathrm{~mm}$ (Hopson 1969), and (b) a haplochromine larvae, Paralabidochromis chilotes, photographed the first day that the mother was no longer collecting the larvae into the buccal cavity upon stimulated disturbance. Note the prominence of the eye. See Appendix B.

$88 \times 30 \mathrm{~mm}(300 \times 300$ DPI $)$ 


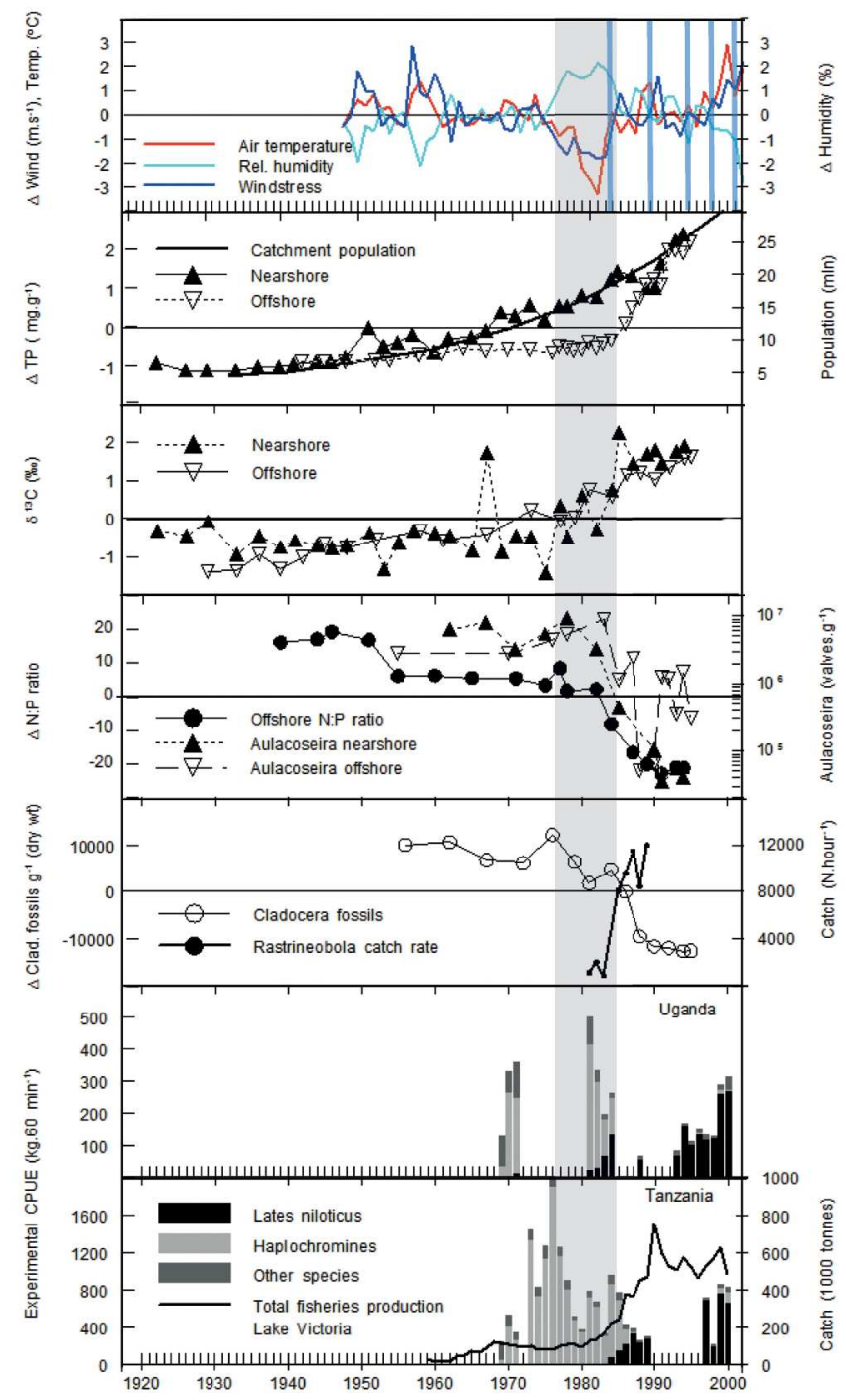

Figure 3 a: Standardised anomalies ((value-mean)/stdev) of over-lake air temperature (oC) (mean=19.6 $\mathrm{sd}=0.26)$, wind speed $(\mathrm{m} / \mathrm{s})($ mean $=2.33, \mathrm{sd}=0.20)$ and humidity $(\%)($ mean $=88,0, \mathrm{sd}=2.42$ ) over the period 1948-2000 (Kalnay et al. 1996). Blue bands: El Niño years

3b: Catchment population $(\mathrm{mln})$; Standardised anomalies of total phosphorus (TP) $(\mathrm{mg} / \mathrm{g})$ inshore Itome core $($ mean $=1.26$, stdev $=0.20, \mathrm{~N}=38) ;$ TP offshore core V96-5MC $($ mean $=1.19$ stdev $=0.74 \mathrm{~N}=30)$ (Hecky et al. 2010).

3c: Standardised anomalies in stable isotopic carbon signatures of sedimentary organic matter. $\delta 13 \mathrm{C}(\% \circ)$ inshore Itome core (mean $=-20.80$, stdev $=1.09 \mathrm{~N}=38)$; offshore V96-5MC core $($ mean= -21.56 , stdev $=$ $0.35, \mathrm{~N}=22$ ) (Hecky et al. 2010).

3d: Anomalies in offshore $\mathrm{N}: \mathrm{P}$ ratio (mean $=37.4, \mathrm{~N}=18$ ); Aulacoseira concentrations in sediment cores

(valves/g dry weight) (nearshore $\mathrm{N}=11$; offshore $\mathrm{N}=14$ ) (Hecky et al. 2010).

3e: Anomalies in cladoceran fossils (number/g dry weight) (mean $=14327, \mathrm{~N}=14$ ) in a core taken from Grant Bay (Uganda) (Bridgeman 2001); Rastrineobola catch rates (N/hour) (Wanink 1999). 
3f, 3g: Catch rates $(\mathrm{kg} / \mathrm{hr})$ of Lates niloticus, Haplochromines and other species from experimental trawl surveys conducted in Tanzania and Uganda (see text and Kolding et al. (2008)). Total fisheries production Lake Victoria from Kolding et al. (2013).

$\Delta$ in front of a legend indicates (standardised) anomalies around the mean. $306 \times 455 \mathrm{~mm}(300 \times 300 \mathrm{DPI})$ 


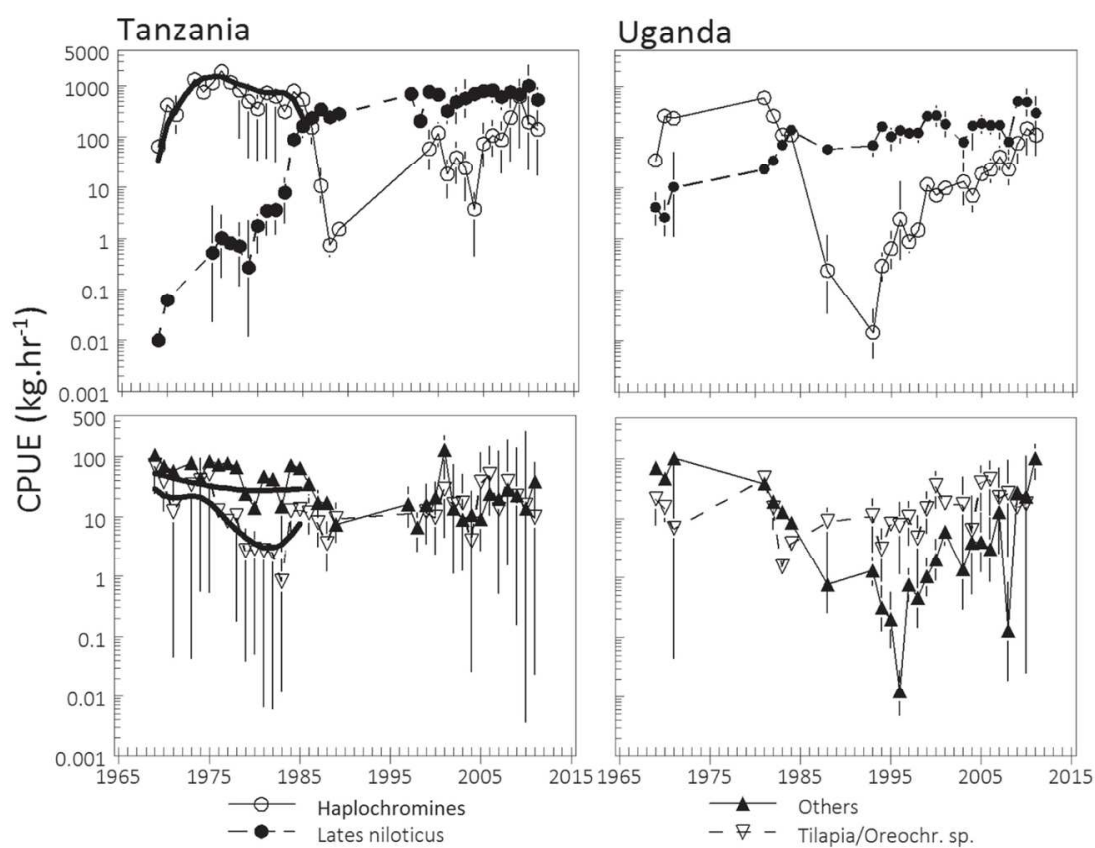

Figure 4. Standardized geometric mean catch per unit effort (CPUE, $\mathrm{kg} / \mathrm{hr}$ ) in experimental trawl surveys in Uganda and Tanzania for all stations less than $40 \mathrm{~m}$ depth for Lates niloticus, haplochromines, tilapiines and other species between 1969 and 2011. Experimental trawlers do not catch Rastrineobola or Caridina, which are not included in "others". Vertical grey areas represent the start of the Nile perch boom in Kenya (1979) and Tanzania (1982) according to Goudswaard et al. (2006). Thick black curve is a spline regression on the developments in haplochromine, tilapiine and other species relative biomass in Tanzania: overall, between 1974 and 1985 and prior to the Nile perch upsurge in 1985, the haplochromine decrease was $9.6 \%$ per year. $139 \times 112 \mathrm{~mm}(300 \times 300 \mathrm{DPI})$ 

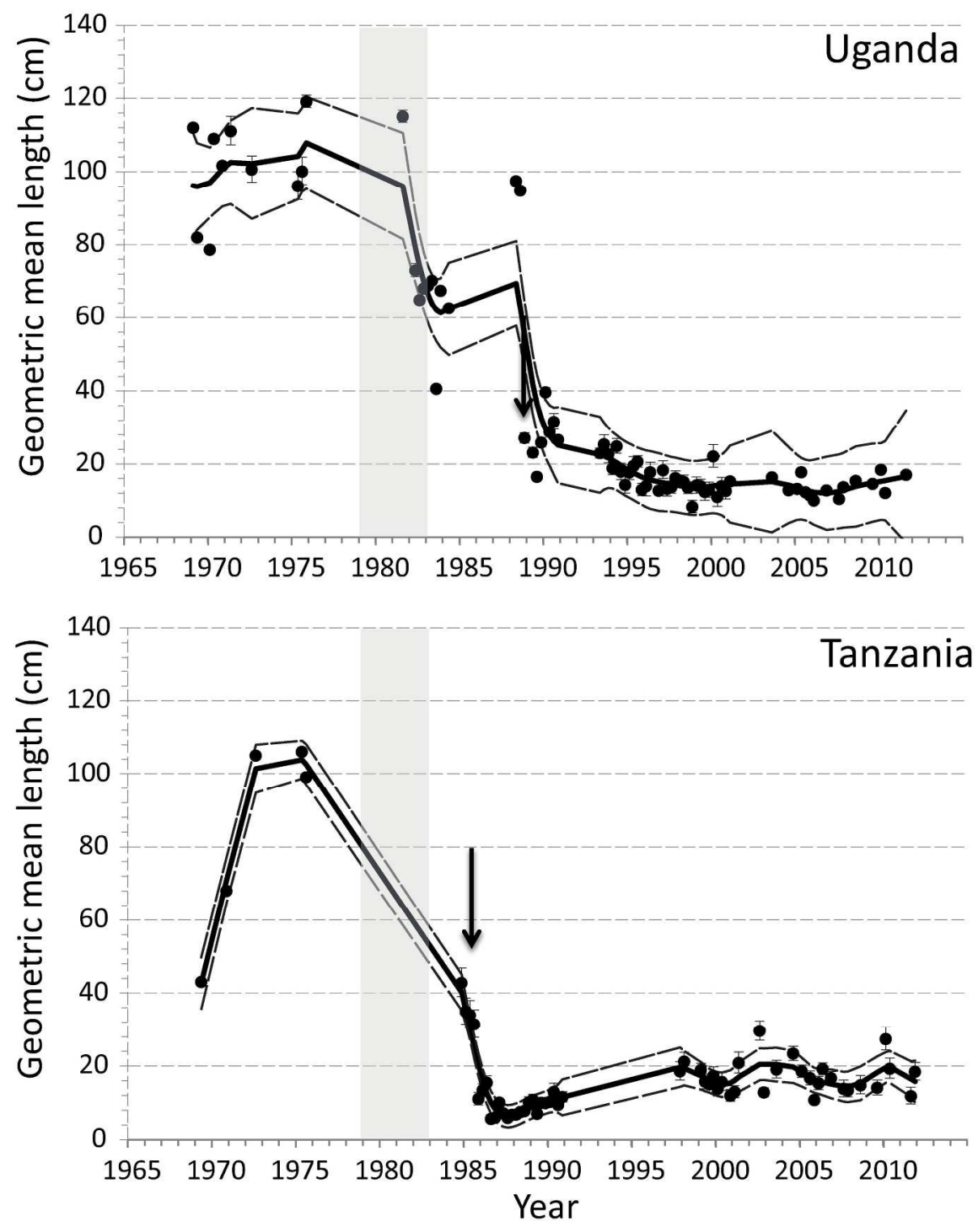

Figure 5. Left: Geometric mean length of Nile perch and $95 \%$ confidence intervals by quarter and year in the catches of the experimental trawl surveys. Vertical grey bar: start of the upsurge defined as catch rates $>45$ $\mathrm{kg} / \mathrm{hr}$ Nile perch (Goudswaard et al. 2008) in respectively Kenya and Uganda (top) and Kenya and Tanzania (bottom). Arrow: first recording in the experimental surveys of the burst in numbers of recruits $<15 \mathrm{~cm}$. $212 \times 278 \mathrm{~mm}$ (300 x 300 DPI) 

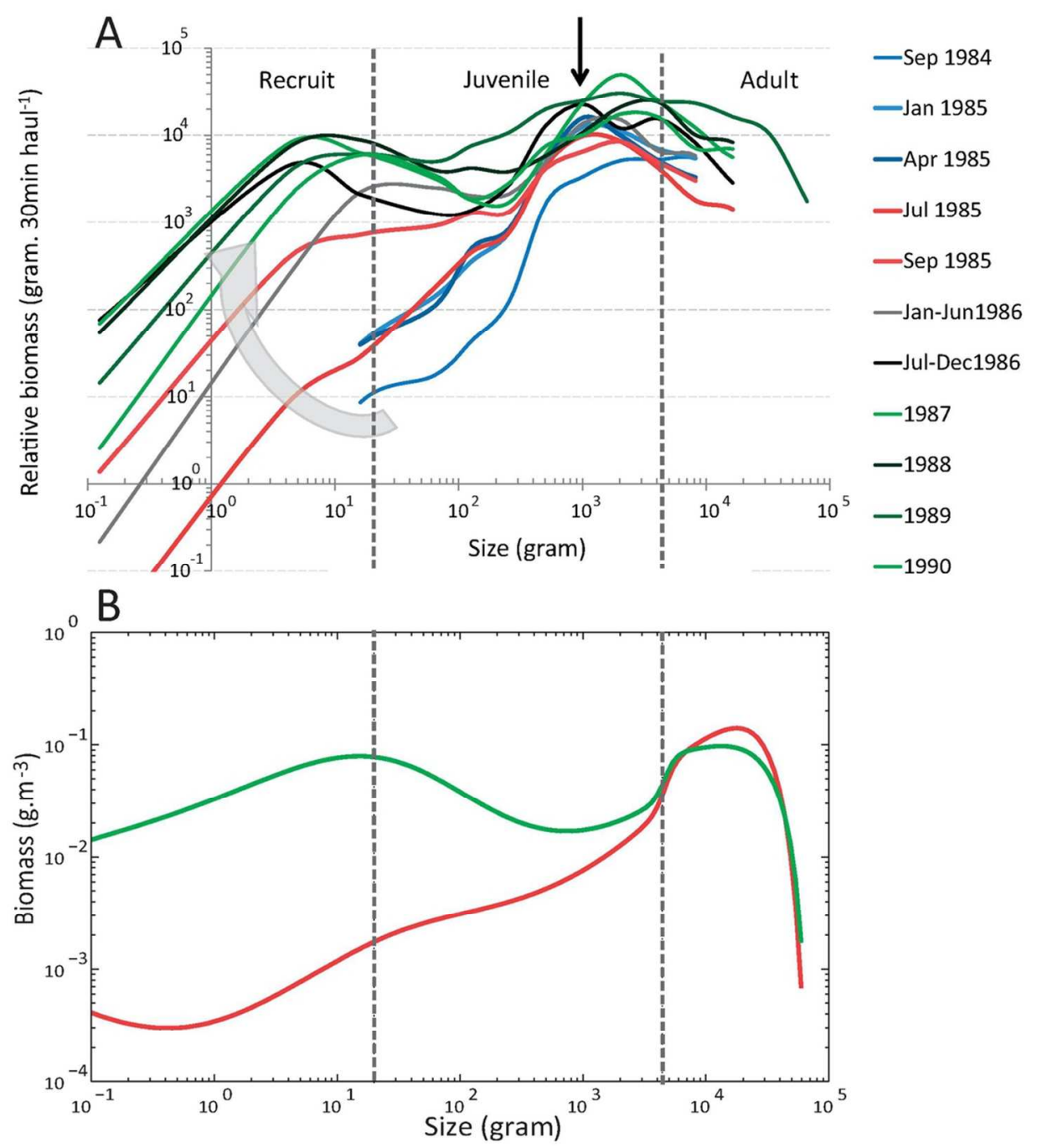

Figure 6. Top: Development of the observed relative biomass-size distribution of Nile perch in the Mwanza Gulf between September 1984 and December 1990 in experimental trawl surveys. The recruitment burst started between July 1985 and December 1985. Prior to that the Nile perch population consisted predominantly of specimen $>500 \mathrm{gr}$. Bottom: two-species size-spectrum model results of the size distribution of Nile perch prior to the switch in co-existence with haplochromines (red line) and post-switch after the extirpation of haplochromines (green line). 

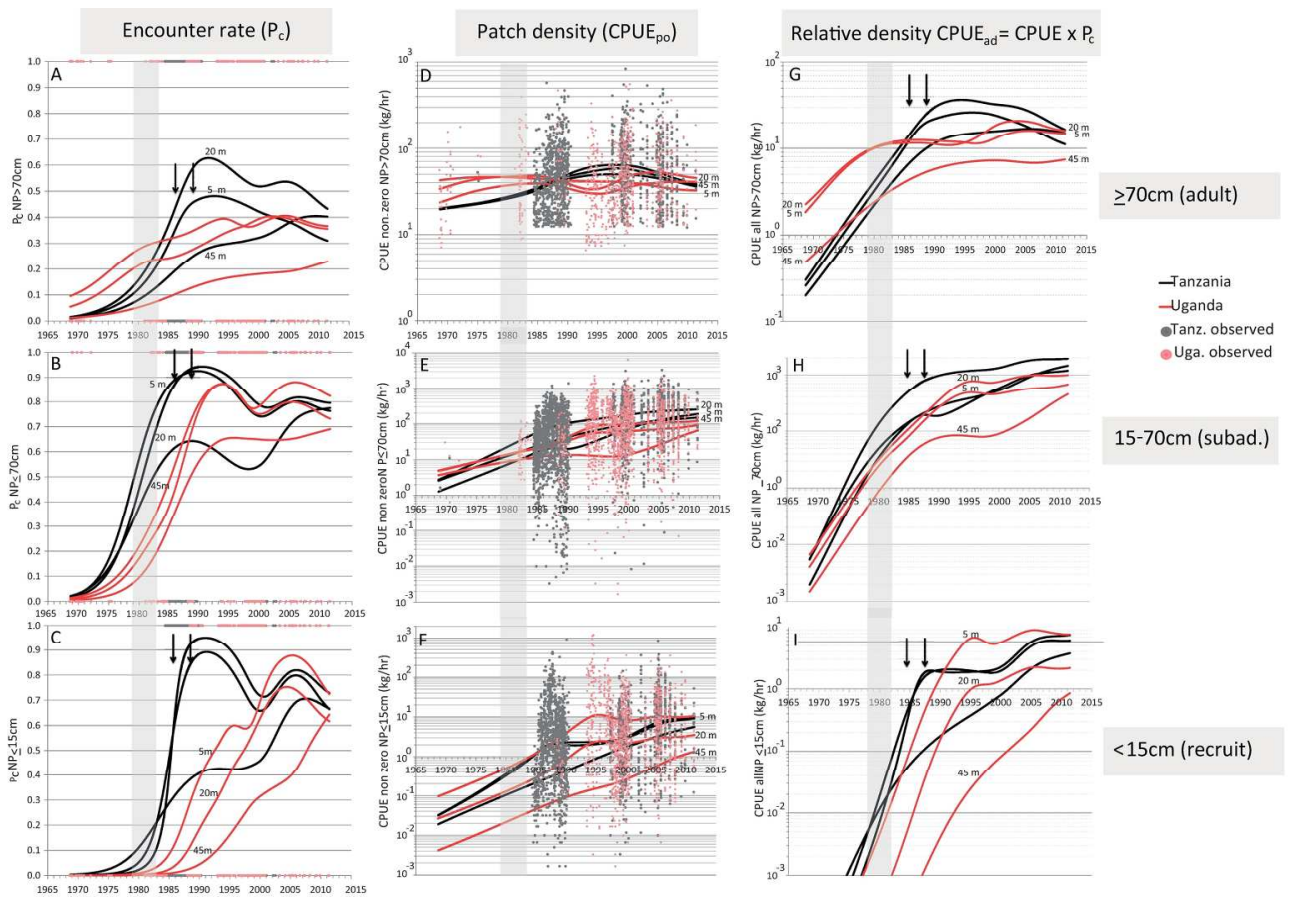

Figure 7. Development in encounter rate (Pc), patch density (CPUEad, $\mathrm{kg} / \mathrm{hr}$ ) and relative density (CPUEad, $\mathrm{kg} / \mathrm{hr}$ ) of adult $(>70 \mathrm{~cm})$, subadult $(>15 \mathrm{~cm}-<70 \mathrm{~cm})$ and recruits $(<15 \mathrm{~cm})$ of Nile perch in trawl surveys in Tanzania and Uganda at 5, 20 and $45 \mathrm{~m}$ depth. Grey and red dots: observed zero and non-zero catches and positive catch rates. Grey bar represent the start of the Nile perch boom in Kenya (1979) and Tanzania (1982); left arrows: start of recruitment in Tanzania (Mwanza Gulf); right arrows: first observed recruitment in Uganda. Vertical indication of depth sequence is the same for both Ugandan and Tanzanian series in a graph at the point it is indicated. $197 \times 134 \mathrm{~mm}$ (300 x 300 DPI) 


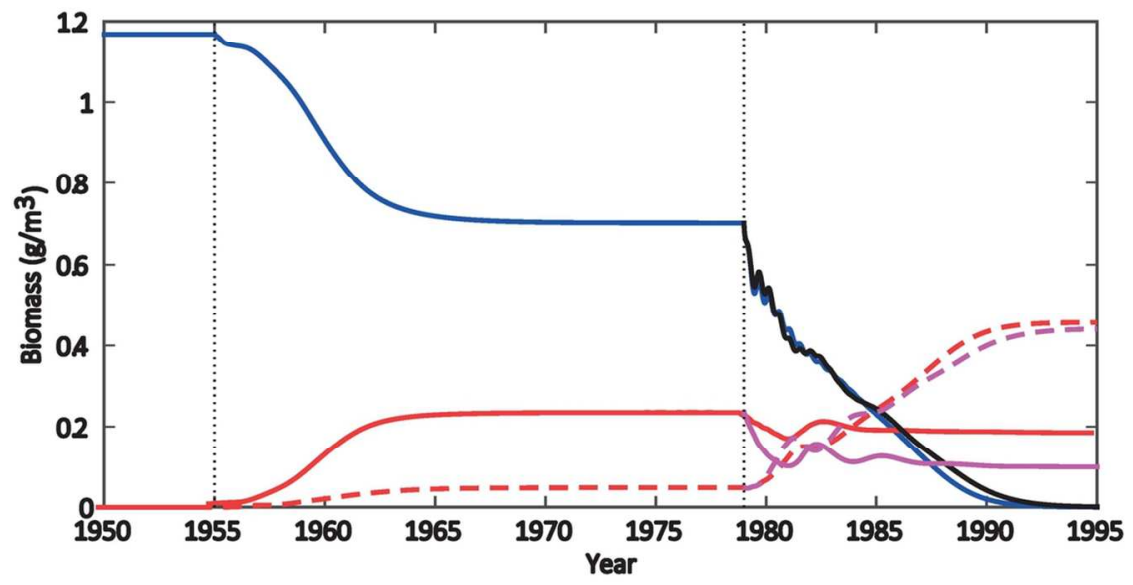

Figure 8. Size-spectrum model time series of the total haplochromine biomass (blue, black), the adult ( $>70$ $\mathrm{cm}$ ) Nile perch biomass (solid red, purple) and the juvenile $(<70 \mathrm{~cm}$ ) Nile perch biomass (dashed red, purple). A small population of large, adult Nile perch was introduced to the model in 1955 and an additional mortality rate of $5 / \mathrm{yr}$ was applied to adult haplochromines from 1979 onwards. The black and purple lines indicate an additional fishing mortality of $0.5 / \mathrm{yr}$ on Nile perch $>40 \mathrm{~cm}$ simultaneous with the additional haplochromine mortality. $113 \times 82 \mathrm{~mm}(300 \times 300$ DPI $)$ 


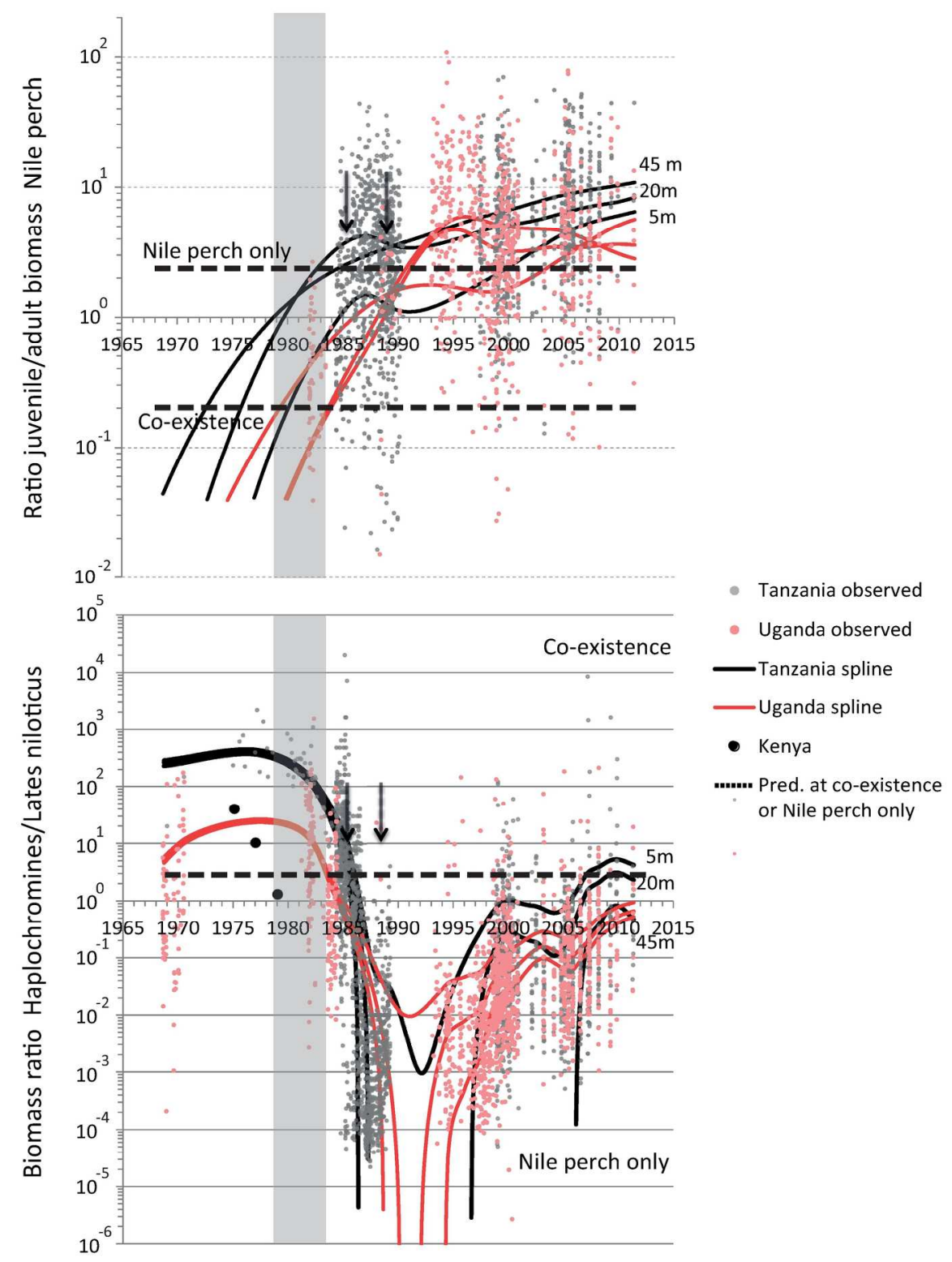

Figure 9. A. Ratio adult $(>70 \mathrm{~cm})$ to juvenile $(<70 \mathrm{~cm})$ Nile perch in experimental trawl surveys. Curves are thin plate spline predictions from a general additive model at 5, 20 and $45 \mathrm{~m}$ depth. Grey bar and arrows as in previous figures. Horizontal lines are the ratios at co-existence (pre-switch) and after extirpation of haplochromines (post switch) predicted by the size-spectrum model

B. Relative biomass ratio of haplochromines:Lates niloticus (CPUE) in experimental trawl surveys. Curves are thin plate spline predictions from a general additive model at 5, 20 and $45 \mathrm{~m}$ depth. Grey bar and arrows as in previous figures. Dotted horizontal line is biomass ratio at coexistence predicted by the size spectrum model.

$180 \times 225 \mathrm{~mm}(300 \times 300$ DPI $)$ 

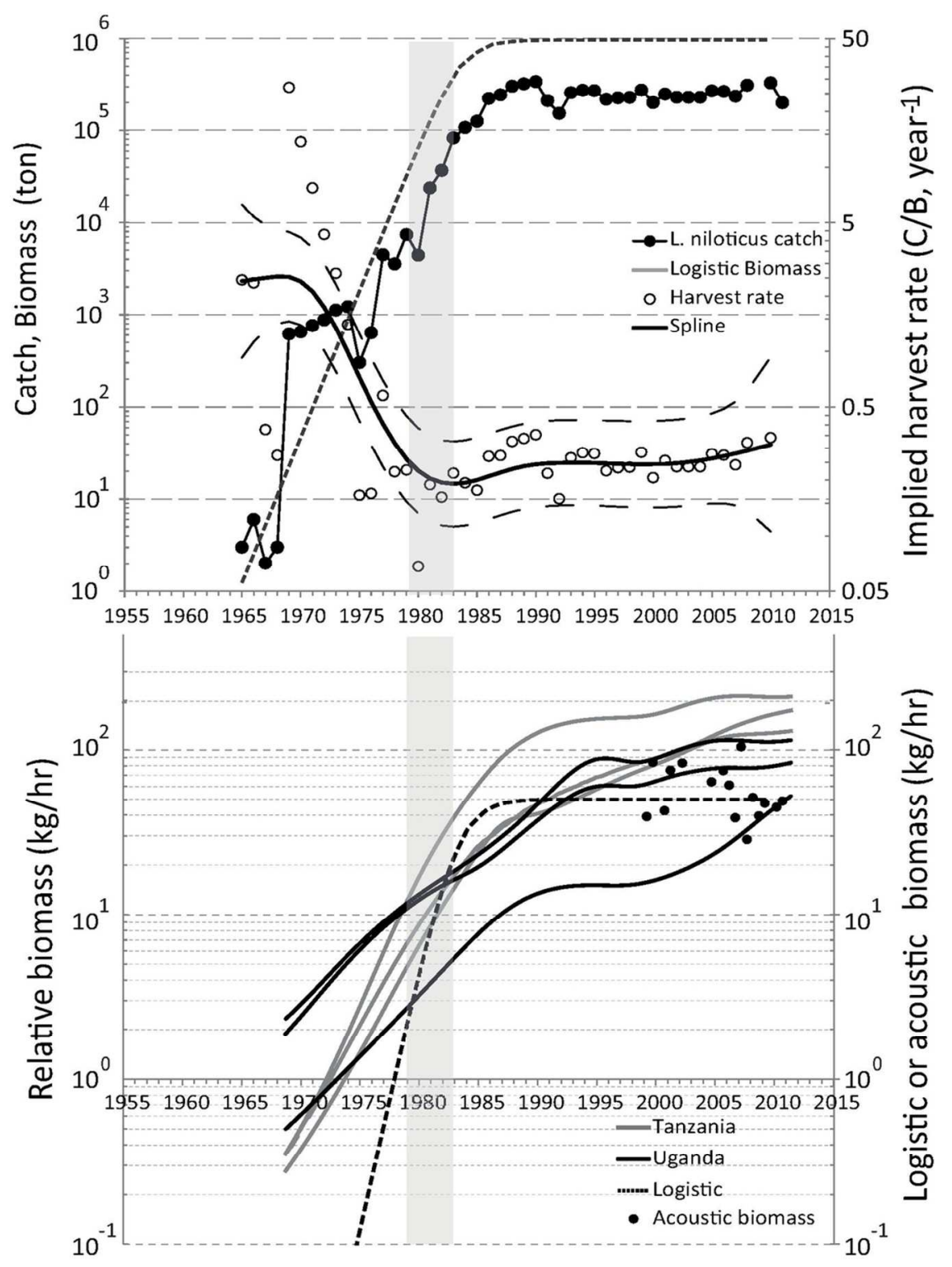

Figure 10. Comparison of the development in Nile perch biomass according to a logistic growth model with an inoculation of $400 \mathrm{gr}, \mathrm{r}=0.73 / \mathrm{yr}$ and $\mathrm{K}=963200$ ton (Downing et al. 2013) with the development in reported catch (top) and relative biomass CPUE ad (bottom) of Nile perch. Top: includes implied harvest rate $(\mathrm{H}=\mathrm{C} / \mathrm{B})$ from the modelled biomass. Bottom: development in relative biomass in Tanzania (broken line) and Uganda (full line) at 5, 20 and 45m depth, as well as absolute biomass estimates from acoustic surveys (black dots) (Everson et al 2013, EAF/LVFO, 2013). Relative, logistic and acoustic biomass are scaled to a swept area of a standard 60 minute trawl haul (3.5 knots, 24.5 m head-rope, $2 \mathrm{~m}$ net depth) amounting to a swept volume of $112300 \mathrm{~m}^{3}$ ( proportional to $4.310-8$ times the volume of Lake Victoria), indicating that acoustic and experimental relative biomass estimates are in the same order of magnitude. 
1

2

3

4

5

6

7

8

\section{APPENDIX A. Climate and limnological data}

Time series of windstress, temperature and relative humidity were taken from NCEP Reanalysis 1 (Kalnay et al. 1996) Gaussian Grid point 1 with Lat $=-0.9524$ S and Lon 31.8750 E. Data are available every six hours; annual averages were calculated in Matlab using the function binaver (Kanamitsu et al. 2002). Maclntyre et al. (2014) indicated that temperature changes computed using surface energy budgets with Reanalysis I data were similar to temperature changes in the lake whereas those from Reanalysis 2 data were inaccurate. Uncertainty exists as to the cause of the low winds and air temperatures and high relative humidity from the late 1970s until the early 1980s. They may result from inaccuracies in melding the pre-satellite modelled data with that including satellite data. However, measured rainfall data from all the meteorological stations in the Lake Victoria basin support the inference of El Nino-like conditions in the late 1970s (Chris Funk and Pete Peterson, personal communication).

Radiometrically dated sediment records of total phosphorous (TP, mg/g), total $\mathrm{N}(\mathrm{mg} / \mathrm{g})$, stable isotopic carbon signatures of as well as Aulacoseira concentrations (valves/g dry weight) are constructed from two sediment cores taken nearshore at Itome (Napoleon Gulf, Uganda, position: $00^{\circ} 13 \mathrm{~N}, 33^{\circ} 14^{\prime} \mathrm{E}$ ) and offshore in Tanzania in the deepest part of the lake west off its center (V96$5 \mathrm{MC}$ ) (position: $01^{\circ} 13.9^{\prime} \mathrm{S}, 33^{\circ} 11.8^{\prime} \mathrm{E}$ ). The two cores (see Hecky et al. (2010) for a full discussion) enable direct comparison of changes in magnitude and timing of significant limnological changes in shallower waters with changes in offshore areas. Cladoceran fossils (number/g dry weight) are taken from in a core taken from Grant Bay (Uganda) (Bridgeman 2001). The sedimentary organic N:P molar ratios are calculated from the TN and TP measured from the cores described. 


\section{APPENDIX B. Experimental trawl surveys on Lake Victoria}

Trawl survey data from Uganda and Tanzania, representing independent replicates from the same lake, were made available through Lake Victoria Fisheries organization (LVFO) and individual researchers in Uganda and Tanzania. Data from lake-wide surveys with the RV-Ibis conducted from 1969 to 1971 were digitized from the original sources recovered at the library of NAFIRRI in Jinja, Uganda. In Uganda the extant data from experimental trawl surveys covered the period from 19811984, 1988 and from 1993-2005 (except 2002) by RV Ibis. Available trawl catches in Tanzania covered the periods 1971-1983 (MS Mdiria) compiled by PC Goudswaard and the HEST surveys from 19841990 (RV Kiboko). Both sets focused on the Mwanza Gulf: information on sampling procedures and sites can be found in Goudswaard (2006). From 1997 onwards the surveys, covering the Tanzanian sector and from 2005 onwards also in Uganda, were carried out with the RV Explorer. RV Ibis and RV Mdiria both used trawl nets with headropes of respectively 24 and $25 \mathrm{~m}$ long with codend mesh sizes of $20-25 \mathrm{~mm}$, fished with a speed of 3.5 knots. With an effective horizontal opening of the trawl off $33.3 \%$ of the head rope length this results in a swept area of $5.3 \mathrm{ha} / \mathrm{hr}$. RV Kiboko used a trawl with a headrope of $18.5 \mathrm{~m}$ and a $20 \mathrm{~mm}$ codend with a trawling speed of $3-4 \mathrm{knots}$ resulting in a swept area of 3.3-4.5 ha/hr (Bergstrand and Cordone 1971, Goudswaard et al. 2006, Okaronon 1999). From 2005 onwards the RV Explorer was run under Standard Operating Procedures (SOPs) developed by LVFO for the collection of data on catch rates and length frequencies through bottom trawling, acoustic surveys, and the environment. The 250-HP, $16.5 \mathrm{~m}$ long RV Explorer was equipped with a trawl net of $24.5 \mathrm{~m}$ head rope and a cod end of $25 \mathrm{~mm}$ mesh size. Towing speed was 3.0 knots, resulting in a swept area of $4.5 \mathrm{ha} / \mathrm{hr}$. Shallow areas, less than $4 \mathrm{~m}$ depth, were not covered due to the vessel draught while rough habitats and rocky substratum were also not sampled.

Catches were recorded by haul and by species category in weight (kg). Haplochromines generally were recorded as one single category; all other species were recorded at least by genus but mostly at the species level. Length-frequencies (nearest $\mathrm{cm}$ standard length) were recorded for Nile 
49 perch in all surveys. In early surveys with the RV lbis the total weight per length-category was

50 recorded as well, but these data were excluded from this analysis. For each haul, duration, location

51 (by name and later also by latitude and longitude) and depth were recorded. For the RV Mdiria no

52 information on depth and location were recorded but the vessel operated in the Mwanza Gulf.

53 Potential sources of bias in using these survey data are discussed in Kolding et al. (2008). 
54

55

56

57

58

59

60

61

62

\section{APPENDIX C. Haplochromine fry size}

Haplochromine fry of several species kept and bred in the laboratory of the Swiss Federal Institute for Aquatic Science and Technology (Eawag), were photographed to obtain an average and range of fry sizes. Photographing was done within two days of termination of maternal brood care in a petri dish on top of a $\mathrm{cm}$ grid. Sizes were converted to weight using a length weight relation for guppies (Poecilia reticulata) with $\mathrm{a}=0.02\left(\mathrm{~g} / \mathrm{cm}^{\mathrm{b}}\right)$ and $\mathrm{b}=3.049$ (Kolding unpublished data). The estimated weights were used to validate the parameter values used in the size-spectrum model (Table C1). 


\begin{tabular}{|c|c|c|c|c|c|}
\hline Species & $\begin{array}{l}\text { Habitat, trophic group, } \\
\text { current status }\end{array}$ & $\begin{array}{l}\text { Days post } \\
\text { first } \\
\text { release }\end{array}$ & $\mathbf{N}$ & $\begin{array}{l}\text { Size (sd) } \\
\mathrm{mm}\end{array}$ & $\begin{array}{c}\text { Weight (sd) } \\
\text { gr }\end{array}$ \\
\hline Pundamilia pundamilia Senga & $\begin{array}{l}\text { Rocky inshore, insectivore } \\
\text { abundant }\end{array}$ & $5-6$ & 10 & $11.8(0.85)$ & $0.033(0.007)$ \\
\hline Pundamilia nyererei Python & $\begin{array}{l}\text { Rocky inshore, } \\
\text { zooplanktivore abundant }\end{array}$ & 4 & 9 & $11.7(0.30)$ & $0.032(0.002)$ \\
\hline Pundamilia nyererei Kissenda & $\begin{array}{l}\text { Rocky inshore, } \\
\text { zooplanktivore abundant }\end{array}$ & 3 & 11 & $11.0(0.32)$ & $0.027(0.002)$ \\
\hline $\begin{array}{l}\text { Pundamilia nyererei } x \\
\text { P. pundamilia }\end{array}$ & $\begin{array}{l}\text { Rocky inshore, } \\
\text { zooplanktivore, insectivore }\end{array}$ & 8 & 12 & $12.8(0.50)$ & $0.043(0.005)$ \\
\hline $\begin{array}{l}\text { Neochromis omnicaeruleus } \\
\text { Makobe }\end{array}$ & $\begin{array}{l}\text { Rocky inshore, algal } \\
\text { scraper abundant }\end{array}$ & 8 & 8 & $13.3(0.98)$ & $0.048(0.011)$ \\
\hline Neochromis sp. (unicuspid) & $\begin{array}{l}\text { Rocky inshore, algal } \\
\text { scraper, abundant }\end{array}$ & 1 & 12 & $11.5(0.26)$ & $0.026(0.002)$ \\
\hline Yssichromis pyrrhocephalus & $\begin{array}{l}\text { Pelagic offshore, } \\
\text { zooplanktivore, recovered }\end{array}$ & 3 & 12 & $11.4(0.51)$ & $0.030(0.004)$ \\
\hline Haplochromis tanaos & $\begin{array}{l}\text { Pelagic inshore, } \\
\text { zooplanktivore, } \\
\text { recovered }\end{array}$ & 3 & 7 & $14.2(0.39)$ & $0.059(0.005)$ \\
\hline Lipochromis melanopterus & $\begin{array}{l}\text { Inshore, } \\
\text { paedophage, } \\
\text { survived }\end{array}$ & 6 & 7 & $14.4(0.37)$ & $0.061(0.005)$ \\
\hline $\begin{array}{l}\text { Paralabidochromis rockkribensis } \\
\text { (1) }\end{array}$ & $\begin{array}{l}\text { Rocky inshore, insectivore } \\
\text { abundant }\end{array}$ & 4 & 8 & $13.2(0.38)$ & $0.046(0.004)$ \\
\hline $\begin{array}{l}\text { Paralabidochromis rockkribensis } \\
\text { (2) }\end{array}$ & & 4 & 9 & $13.4(0.60)$ & $0.049(0.007)$ \\
\hline $\begin{array}{l}\text { Paralabidochromis chilotes } \\
\text { Makobe (1) }\end{array}$ & $\begin{array}{l}\text { Rocky inshore, insectivore } \\
\text { abundant }\end{array}$ & 10 & 14 & $14.6(0.51)$ & $0.063(0.006)$ \\
\hline $\begin{array}{l}\text { Paralabidochromis chilotes } \\
\text { Makobe (2) }\end{array}$ & & 9 & 13 & $13.9(0.80)$ & $0.055(0.009)$ \\
\hline Astatotilapia tweddlei (1) & Riverine, & 6 & 5 & $10.0(0.13)$ & $0.020(0.001)$ \\
\hline A. tweddlei (2) & Generalist, Lake Chilwa & 8 & 6 & $10.7(0.34)$ & $0.025(0.002)$ \\
\hline A. calliptera & $\begin{array}{l}\text { Riverine generalist, Lake } \\
\text { Malawi }\end{array}$ & $2-3$ & 10 & $11.8(0.21)$ & $0.033(0.002)$ \\
\hline A. burtoni & $\begin{array}{l}\text { Riverine, generalist } \\
\text { Lake Tanganyika }\end{array}$ & 7 & 10 & $13.7(0.61)$ & $0.053(0.007)$ \\
\hline A. sp. Lake Challa & $\begin{array}{l}\text { Riverine generalist, Lake } \\
\text { Challa }\end{array}$ & $6-7$ & 11 & $10.9(0.45)$ & $0.026(0.003)$ \\
\hline $\begin{array}{l}\text { Average lake } \\
\text { Average riverine }\end{array}$ & & & & & $\begin{array}{l}0.044 \\
0.031\end{array}$ \\
\hline
\end{tabular}

Table C1. Larval size and weight of a range of haplochromine cichlids measured the first day that the mother was no longer collecting larvae into the buccal cavity upon stimulated disturbance. Days post first release captures the variation in the duration of mouth brood care after first release. Number in brackets indicates different individuals of the same species. $\mathrm{N}=$ number of fry measured $\mathrm{sd}=$ standard deviation. 


\section{APPENDIX D. Experimental survey data standardisation and time series analysis}

Catch rates from the experimental fishery in biomass $(\mathrm{kg})$ by species were corrected for trawl duration to a standard haul of 60 minutes using total biomass of all species

1) $\quad C P U E_{i x}^{S}=C P U E_{i}\left(\frac{\bar{f}}{f_{i x}}\right)^{\beta}$

Where $\mathrm{CPUE}^{\mathrm{s}}$ ix is the standardised CPUE for the i-th fishing trip of vessel $\mathrm{x}\left(\mathrm{kg}\right.$.haul $\left.{ }^{-1}\right)$ and $\bar{f}$ is the common trawl duration of 60 minutes; $\bar{f} / f_{i}$ represents the reciprocal of the standardised trip and $\beta=$ $\beta_{1}+\beta_{2}$ is the coefficient for this effort measure from the following separate slopes model (Tsehaye et al. 2007)

2) $\quad E\left(\log _{10}\left(\right.\right.$ CPUE $\left.\left._{i x}\right)\right)=\alpha+$ vessel $_{i x}+B_{1} \cdot \log _{10}\left(\right.$ duration $\left._{i}\right)+B_{2}$ vessel $_{i x} \cdot \log _{10}\left(\right.$ duration $\left._{i}\right)+\varepsilon_{i x}$ iid $^{\sim}$ $N\left(0, \sigma^{2}\right)$.

No significant effect of vessel was detected for total Nile perch weight in the catch. Weights calculated from length frequencies were standardized to a 60 minute trawl haul duration with $\beta=$ 0.73 .

Time series analysis: hurdle model:

For each haul a new variable was constructed with a probability of catch (Pc) or encounter rate equal to 0 for no catch and 1 for a positive catch (weight $>0$ ) as well as a variable containing positive catch weights. Zero catches are assumed to be structural, related to below detection limits or non-presence of fish; the probability of false zeroes as a result of observation or sampling errors is assumed to be low and constant over the observation period.

Developments of $\mathrm{P}_{\mathrm{c}}$ and $\mathrm{CPUE}_{\mathrm{po}}$, the positive trawl catches or patch density, over time and depth were examined with maximum likelihood methods through a Generalized Additive Model (GAM) with a thin plate regression spline (TPS), 
91

92

3)

$$
E\left(Y_{i} \mid \text { date }, \text { depth }\right)=\beta_{0}+s(\text { date, depth })+\varepsilon_{i} \text { iid } N\left(0, \sigma^{2}\right)
$$

Where estimates $E(Y)$ with $Y=P_{c}$ or $\log _{10}\left(C P U E_{p o}\right)$ are obtained for adults, sub-adults and recruits sampled at a date and depth, and $S\left(x_{1}, x_{2}\right)$ is the nonparametric thin plate smoothing function for the independent variables $x_{1}=$ date and $x_{2}=$ depth. The model was implemented specifying a binomial and Gaussian distribution respectively for $P_{c}$ and $\log _{10}\left(C P U E_{p o}\right)$ with their canonical link functions. The value of the smoothing parameter selected by generalized cross validation (GCV) led to jagged over-parameterised curves utilising a high number of degrees of freedom that obscured the general pattern in developments. As the calculation of the thin plate spline smoother was computationally intensive, a GAM model estimating separate splines and linear regressors for depth and date was used to estimate the appropriate allowable degrees of freedom (df) for the smoothing parameter. After obtaining a satisfactory regression spline with limited change in the deviance of the final estimate, the sum of the two df's for depth and date then were used in the thin plate spline estimate. Analyses were done separately for Uganda and Tanzania. To examine developments at different depths estimates of Nile perch encounter rates and catch rates were calculated for $5 \mathrm{~m}, 20 \mathrm{~m}$ and $45 \mathrm{~m}$. Developments in $\mathrm{CPUE}_{\mathrm{ad}}$ were obtained by multiplying the model results for $\mathrm{P}_{\mathrm{c}}$ and $\mathrm{CPUE}_{\mathrm{po}}$.

A thin plate spline regression was also used to examine the developments over time and depth of two abundance ratios: the juvenile Nile perch: adult Nile perch $(\mathrm{J} / \mathrm{A})$ and the Haplochromine: Nile perch $(\mathrm{H} / \mathrm{N})$ biomass ratio. To obtain normality and homoscedasticity in the residuals and take account of 0 values in the trawls, the J/A ratio was transformed as $\left(Y+10^{-4}\right)^{0.2}$. The H/A ratio was transformed as $\left(\mathrm{Y}+10^{-7}\right)^{0.44}$. Powers of the transformation were estimated through a search over parameter values of $\lambda$ of the BoxCox-transformation minimizing the Akaike Information Criterion (AIC) and the Schwartz's Bayesian Criterion (SBC). Values predicted by the size-spectrum model of both abundance ratio's at the Nile perch switch were compared with the observed values at the moment in time that recruitment of $<15 \mathrm{~cm}$ Nile perch commenced. All statistical models were 
116 implemented using SAS/STAT ${ }^{\circledR}$ software Version 8 of the SAS system for Windows using the GLM, 117 GENMOD and GAM procedures. Model results are in Table D1.

$118 \quad P / B$ Estimates

119 A conservative $\mathrm{P} / \mathrm{B}$ estimate of 1.4 / $\mathrm{yr}$ was used in the calculations of haplochromine

120 productivity. P/B estimates for Lake Victoria haplochromine cichlids are scant, but this value is in the

121 lower part of the range of fished haplochromines from Lake Malawi that had an average $P / B=3.1 / y r$

$122(\mathrm{~N}=22, \mathrm{CV}=30 \%, \max =4.7 / \mathrm{yr}, \mathrm{min}=1.6 / \mathrm{yr}$ ) (Duponchelle et al. 2000) and from Lake Malombe, 123 average $\mathrm{P} / \mathrm{B}=1.6 / \mathrm{yr}(\mathrm{N}=5, \mathrm{CV}=46 \%, \mathrm{~min}=0.56 / \mathrm{yr}, \mathrm{max}=2.7 / \mathrm{yr})$ (Weyl et al. 2005). 


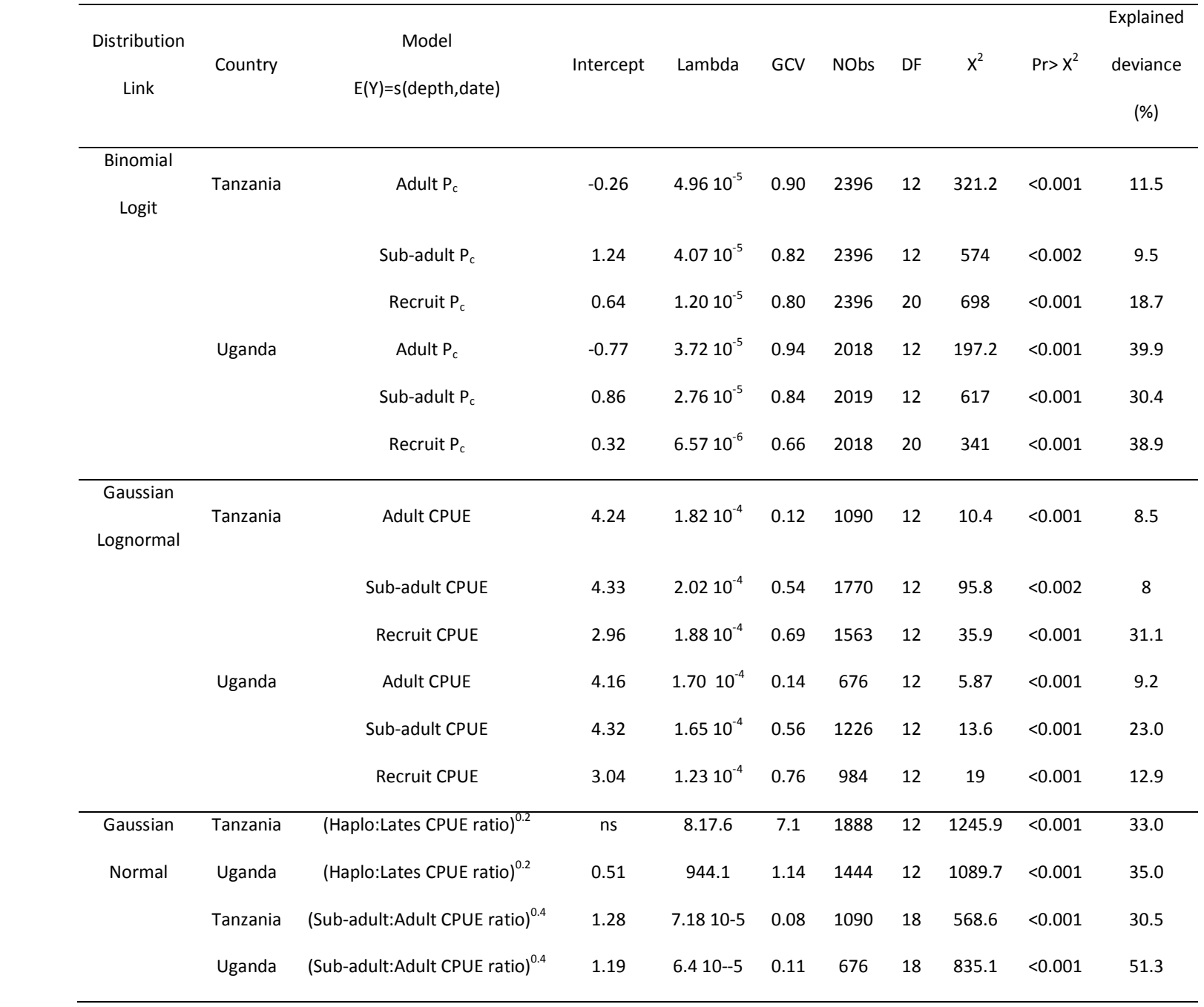

Table D1. Results GAM analysis Pc and CPUE of adult $(\geq 70 \mathrm{~cm})$, sub-adult $(<70 \mathrm{~cm}, \geq 15 \mathrm{~cm})$ and recruits $(<15 \mathrm{~cm})$ of Nile perch and the ratios juvenile/adult Nile perch CPUE and haplochromines/Nile perch CPUE. Nobs $=$ Number of observations used in the analysis, DF= final degrees of freedom used in the thin plate spline regression. Intercepts all significant at $\operatorname{Pr}>|t|<0.05$, ns is non-significant. Explained deviance is the ratio of the residual deviance of the final estimate of the model and the total estimated deviance of the null model $E(Y)=$ intercept. 


\begin{tabular}{|c|c|}
\hline$\frac{\partial u_{i}}{\partial t}=-\frac{\partial}{\partial x}\left(\varepsilon_{i} g_{i} u_{i}\right)+\frac{b_{i} R_{i} e^{-x}}{2}-\left(\mu_{i}+\mu_{n, i}+\mu_{e, i}\right) u_{i}$ & $\begin{array}{l}\text { Rate of change of density } u_{i}(x) \\
\text { of species I and body size } w_{0} e^{x}\end{array}$ \\
\hline$g_{i}(x)=A_{i} K e^{\left(\alpha_{i}-1\right) x} \sum_{j} \theta_{i j} \int e^{x^{\prime}} s_{i}\left(e^{x-x^{\prime}}\right) u_{j}\left(x^{\prime}\right) v_{j}\left(x^{\prime}\right) d x^{\prime}$ & $\begin{array}{l}\text { Mass-specific food assimilation } \\
\text { rate }\end{array}$ \\
\hline$\mu_{i}(x)=v_{i}(x) \sum_{j} A_{j} \theta_{j i} \int e^{\alpha_{j} x^{\prime}} s_{j}\left(e^{x^{\prime}-x}\right) u_{j}\left(x^{\prime}\right) d x^{\prime}$ & Predation mortality rate \\
\hline$\mu_{n, i}(x)=\frac{\mu_{0, i} \exp \left(-\xi\left(x-x_{i, 0}\right)\right) g_{i}\left(x_{i, 0}\right)}{g_{i}(x)}$ & $\begin{array}{l}\text { Intrinsic non-predation mortality } \\
\text { rate }\end{array}$ \\
\hline$R_{i}=\left(1-\varepsilon_{i}(x)\right) g_{i}(x) u_{i}(x) d x$ & Reproduction rate of species $\mathrm{i}$ \\
\hline $1-\varepsilon_{i}(x)=\left(1+\exp \left(-\rho_{i, m}\left(x-x_{i, m}\right)\right)\right)^{-1} \exp \left(\rho_{i}\left(x-x_{i, \infty}\right)\right)$ & $\begin{array}{l}\text { Proportion of assimilated } \\
\text { biomass used for reproduction }\end{array}$ \\
\hline$s_{i}\left(e^{r}\right)= \begin{cases}C \exp \left(-\frac{\left(r-\beta_{i}\right)^{2}}{2 \sigma_{i}^{2}}\right), & r>0 \\
0, & r \leq 0\end{cases}$ & $\begin{array}{l}\text { Feeding kernel as a function of } \\
\text { log predator:prey body mass } \\
\text { ratio } r\end{array}$ \\
\hline$\theta=\left[\begin{array}{ll}1 & 1 \\
1 & 1\end{array}\right]$ & $\begin{array}{l}\theta_{i j} \text { is the preference of species I } \\
\text { for prey of species } \mathrm{j}\end{array}$ \\
\hline$b_{i}(x)=\delta\left(x-x_{i, 0}\right)$ & $\begin{array}{l}\text { Distribution of egg sizes for } \\
\text { species i }\end{array}$ \\
\hline$v_{i}(x)=H\left(x-x_{i, l}\right)$ & Vulnerability to predation \\
\hline$u_{0}(x)= \begin{cases}u_{0,0} e^{(1-\gamma) x}, & x \leq x_{0, \max } \\
0, & x>x_{0, \max }\end{cases}$ & $\begin{array}{l}\text { Abundance of plankton of body } \\
\text { size } w_{0} e^{x}\end{array}$ \\
\hline
\end{tabular}

The external mortality function $\mu_{e, i}(x)$ is used to apply size- and species-dependent mortalities due to external factors, such as fishing or habitat degradation. $H(x)$ is the Heaviside function (equal to 0 if $x<0$ and equal to 1 if $x>0$ ) and $\delta(x)$ is the Dirac delta function (equal to 0 if $x \neq 0$ and with the property $\left.\int \delta(x) d x=1\right)$.

\section{Two-patch model with dispersal}

In a single patch, the dynamics of $n$ species size spectra, $\mathbf{u}(x)=\left(u_{1}(x), \ldots, u_{n}(x)\right)$, can be written compactly in terms of a nonlinear operator $N$ :

$$
\frac{\partial \mathbf{u}}{\partial t}=N(\mathbf{u})
$$


142 Suppose $\mathbf{u}=\mathbf{u}^{*}$ is an equilibrium of the single-patch model, i.e. $N\left(\mathbf{u}^{*}\right)=0$. The stability of $\mathbf{u}^{*}$ is 143 determined by the eigenvalues of the linearization $L$ of the operator $N$ about $\mathbf{u}^{*}$. An eigenvalue $\lambda$ of $144 \quad L$ satisfies

$$
L \mathbf{v}=\lambda \mathbf{v}
$$

145 for some function $\mathbf{v}(x)$. The equilibrium is stable if $\operatorname{Re}(\lambda)<0$ for all eigenvalues $\lambda$.

146 Now suppose the system is separated into two distinct patches, with size spectra $\mathbf{u}_{1}$ and $\mathbf{u}_{2}$ 147 respectively. If the dynamics within the two patches are the same and the patches are coupled by 148 passive dispersal, then the dynamics are described by

$$
\begin{aligned}
& \frac{\partial \mathbf{u}_{1}}{\partial t}=N\left(\mathbf{u}_{1}\right)+c_{1} D(x)\left(\mathbf{u}_{2}-\mathbf{u}_{1}\right), \\
& \frac{\partial \mathbf{u}_{2}}{\partial t}=N\left(\mathbf{u}_{2}\right)+c_{2} D(x)\left(\mathbf{u}_{1}-\mathbf{u}_{2}\right),
\end{aligned}
$$

149

150

where $c_{i}>0$ is a constant inversely proportional to the volume of patch $i$ and $D(x)$ is a diagonal matrix such that $d_{i i}(x) \geq 0$ is the inter-patch dispersal rate for a individuals of species $i$ and size $x$.

Clearly the single-patch equilibrium $\mathbf{u}_{1}=\mathbf{u}_{2}=\mathbf{u}^{*}$ is also an equilibrium of the two-patch model. The stability of this equilibrium is determined by the eigenvalues $\mu$ of the linearization of the two-patch model. These eigenvalues satisfy

$$
\begin{aligned}
& L \mathbf{v}_{1}+c_{1} D\left(\mathbf{v}_{2}-\mathbf{v}_{1}\right)=\mu \mathbf{v}_{1}, \\
& L \mathbf{v}_{2}+c_{2} D\left(\mathbf{v}_{1}-\mathbf{v}_{2}\right)=\mu \mathbf{v}_{2},
\end{aligned}
$$

for some pair of functions $\left(\mathbf{v}_{1}(x), \mathbf{v}_{2}(x)\right)$. Clearly, setting $\mathbf{v}_{1}=\mathbf{v}_{2}=\mathbf{v}$ and $\mu=\lambda$ satisfies these equations. So if $\lambda$ is an eigenvalue of the single-patch equilibrium, it is also an eigenvalue of the corresponding two-patch equilibrium. This shows that if the single-patch equilibrium is unstable then the corresponding two-patch equilibrium must also be unstable.

Also, setting $\mathbf{v}_{2}=-c_{2} / c_{1} \mathbf{v}_{1}$ gives

$$
L \mathbf{v}_{1}-\left(c_{1}+c_{2}\right) D \mathbf{v}_{1}=\mu \mathbf{v}_{1}
$$


159

160

161

162

163

164

165

166

167

168

169

170

171

172

173

174

175

176

177

178

179

Hence, the remaining eigenvalues of the two-patch equilibrium are the eigenvalues of the linear operator $M$, defined by

$$
M \mathbf{v}=L \mathbf{v}-\left(c_{1}+c_{2}\right) D \mathbf{v}
$$

If the rate of dispersal is the same for all size classes and all species then $D=d I$ where $d>0$ is the constant rate of dispersal and $I$ is the identity. Hence,

$$
M=L-\left(c_{1}+c_{2}\right) d I
$$

and the eigenvalues of $M$ are $\mu=\lambda-\left(c_{1}+c_{2}\right) d$ and so $\operatorname{Re}(\mu)<\operatorname{Re}(\lambda)$.

If dispersal is species- and/or size-dependent, but is relatively weak (small $D(x)$ ), the eigenvalues of $M$ will be close to the eigenvalues of $L$. If dispersal is strong (large $D(x)$ ), the eigenvalues of $M$ will all have negative real part.

In any of these three cases (i. weak dispersal limit, ii. strong dispersal limit, or iii. equal dispersal for all species and sizes), the two-patch equilibrium will have the same stability as the corresponding single-patch equilibrium. For intermediate dispersal, it is possible that the leading eigenvalue of $M$ will have positive real part, even though the leading eigenvalue of $L$ has negative real part. In other words, the right rate of dispersal between patches could destabilize an equilibrium that is stable in the single-patch model.

For the Nile perch - haplochromine model in the absence of additional external mortality on haplochromines, the coexistence state is stable and the Nile perch only state is unstable. This means that, in a single patch, the Nile perch can never drive the haplochromines to complete collapse.

Adding dispersal between patches to the model does not change this prediction because, as shown above, dispersal can never stabilize the unstable Nile-perch only equilibrium. It is possible that dispersal could destabilize the coexistence state. This could lead to periodic solutions (similar to a predator-prey cycle), asymmetric solutions (e.g. large Nile perch population and small haplochromine 
180 population in patch 1 and vice versa in patch 2) or more complex dynamics. However, it cannot lead 181 to extirpation of the haplochromines in either patch. 
Bergstrand, E., and Cordone, A.J. 1971. Exploratory bottom trawling in Lake Victoria. African Journal of Tropical Hydrobiology and Fisheries (Kenya) 1(1): 13 - 23.

Bridgeman, T.B. 2001. The ecology and paleolimnology of food web changes in Lake Victoria, East Africa, University of Michigan, Ann Arbor MI, USA.

Duponchelle, F., Ribbink, A.J., and (eds.). 2000. Fish Ecology Report. Lake Malawi/Nyasa/Niassa Biodiversity Conservation Project. SADC/GEF (Southern African Development Community, Gaborone, Botswana / Global Environmental Facility, Washington, D.C.).

Goudswaard, P.C. 2006. Causes and effects of the Lake Victoria ecological revolution. PhD, Faculty of Mathematics and Naturals Sciences and those of Medicine, Leiden University, Leiden.

Goudswaard, P.C., Witte, F., and Wanink, J.H. 2006. The shrimp Caridina nilotica in Lake Victoria (East Africa), before and after the Nile perch increase. Hydrobiologia 563: 31 - 34.

Hecky, R.E., Mugidde, R., Ramlal, P.S., Talbot, M.R., and Kling, G.W. 2010. Multiple stressors cause rapid ecosystem change in Lake Victoria. Freshwater Biology 55: 19-42.

Kalnay, E., Kanamitsu, M., R.Kistler, Collins, W., D.Deaven, Gandin, L., Iredell, M., Saha, S., White, G., Woollen, J., Zhu, Y., Chelliah, M., Ebisuzaki, W., Higgins, W., Janowiak, J., Mo, K.C., Ropelewski, C., Wang, J., Leetmaa, A., Reynolds, R., Jenne, R., and D.Joseph. 1996. The NCEP/NCAR 40-year reanalysis project. Bull. Am. Met. Soc. 77: $437-471$.

Kanamitsu, M., Ebisuzaki, W., Woollen, J., Yang, S.-K., Hnilo, J.J., Fiorino, M., and Potter, G.L. 2002. NCEP-DEO AMIP-II Reanalysis (R-2). Bulletin of the Atmospheric and Meteorologiocal Society 83(1631 - 1643).

Kolding, J., Zwieten, P.A.M.v., Mkumbo, O., Silsbe, G., and Hecky, R.E. 2008. Are the Lake Victoria Fisheries Threatened by Exploitation or Eutrophication? Towards an Ecosystem-based Approach to Management. In The Ecosystem Approach to Fisheries. Edited by G. Bianchi and H.R. Skjoldal. CAB International, Rome. pp. 309 354

MacIntyre, S., Romero, J.R., Silsbe, G.M., and Emery, B.M. 2014. Stratification and horizontal exchange in Lake Victoria, East Africa. Limnology and Oceanography [Limnol Oceanogr] 59(5): 34.

Okaronon, J.O. 1999. The fish stocks of Lake Victoria. In Report on third Fisheries Data Working Group (FIDAWOG) workshop held at the Triangle Hotel, Jinja, 29 March to 1 April 1999. Edited by D.a.C. Tweddle, I.G. Fisheries Data Working Group of the Lake Victoria Fisheries Research Project, Jinja, Uganda. pp. 30-37. Tsehaye, I., Machiels, M.A.M., and Nagelkerke, L.A.J. 2007. Rapid shifts in catch composition in the artisanal Red Sea reef fisheries of Eritrea. Fish. Res. 86(1): 58-68.

Weyl, O.L.F., Booth, A.J., Mwakiyongo, K.R., and Mandere, D.S. 2005. Management recommendations for Copadichromis chrysonotus (Pisces: Cichlidae) in Lake Malombe, Malawi, based on per-recruit analysis. Fish. Res. 71(2): 165-173. 